NBER WORKING PAPER SERIES

\title{
HOW IS MACRO NEWS TRANSMITTED \\ TO EXCHANGE RATES?
}

\author{
Martin D. D. Evans \\ Richard K. Lyons \\ Working Paper 9433 \\ http://www.nber.org/papers/w9433
NATIONAL BUREAU OF ECONOMIC RESEARCH
1050 Massachusetts Avenue
Cambridge, MA 02138
January 2003

This paper was circulated under the previous title "Why Order Flow Explains Exchange Rates." We thank the following for helpful comments: Brian Boyer, Anusha Chari, Frank Diebold, Jon Faust, Simon Gervais, Aditya Kaul, Antonio Mello, John Rogers, Andrew Rose, and seminar participants at the Empirical Exchange Rate Models conference (Sept. 2001), the American Finance Association meetings (Jan. 2002), the Yale Market Microstructure conference (June 2002), U.C. Berkeley, Alberta, Michigan, London Business School, the New York Fed, Aix-Marseille, and Virginia. Both authors thank the National Science Foundation for financial assistance. The views expressed herein are those of the authors and not necessarily those of the National Bureau of Economic Research.

(C) 2003 by Martin D. D. Evans and Richard K. Lyons. All rights reserved. Short sections of text not to exceed two paragraphs, may be quoted without explicit permission provided that full credit including, (C) notice, is given to the source. 
How is Macro News Transmitted to Exchange Rates?

Martin D. D. Evans and Richard K. Lyons

NBER Working Paper No. 9433

January 2003

JEL No. F31

\section{ABSTRACT}

This paper tests whether macroeconomic news is transmitted to exchange rates via the transactions process and if so, what share occurs via transactions versus the traditional direct channel. We identify the link between order flow and macro news using a heteroskedasticity-based approach, a la Rigobon and Sack (2002). In both daily and intra-daily data, order flow varies considerably with macro news flow. At least half of the effect of macro news on exchange rates is transmitted via order flow.

Martin D. D. Evans

Department of Economics

Georgetown University

Washington DC 20057

and NBER

evansm1@georgetown.edu
Richard K. Lyons

Haas School of Business, UC Berkeley

Berkeley, CA 94720-1900

and NBER

lyons@haas.berkeley.edu 


\section{How Is Macro News Transmitted to Exchange Rates?}

In macroeconomic models of exchange rates, news maps directly into prices. The effect of news on currency demands in these models is common knowledge and transactions though perhaps engendered by the change in exchange ratesplay no role in causing the change. In microeconomic models of asset prices, in contrast, transactions do play a causal role in price determination (e.g., Glosten and Milgrom 1985, Kyle 1985). The causal role arises because transactions convey information that is not common knowledge. In this paper we test whether any part of the effect of news on exchange rates is transmitted via transactions and, if so, what share is transmitted that way versus the traditional direct channel.

That transactions might play a role is motivated by recent empirical work demonstrating a link between signed transaction volume (order flow) and nominal exchange rate changes. ${ }^{1}$ In the models employed by these papers, order flow affects exchange rates as a proximate determinant. The underlying determinant, which theory labels information, is not specified, nor is it directly tested. This leaves open the nagging question of what really drives the order flow. This paper is an attempt to address that question by examining whether macroeconomic news might be a determinant of order flow. This question is distinct from whether volume is determined by news, a well-established property of many speculative markets (see, e.g., Fleming and Remolona 1999). ${ }^{2}$

1 See, e.g., Payne (1999), Rime (2000), Evans (2002), and Evans and Lyons (2002a). Order flow-concept from microstructure finance-is the cumulation over time of signed trades. Trades are signed according to whether the initiator is buying or selling. (The marketmaker posting the quote is the non-initiating side.) For example, a sale of 1 unit by a trader acting on a marketmaker's quote is order flow of 4 . In rational-expectations models, order flow is undefined because all transactions in that setting are symmetric. A large empirical literature within finance shows that signing trades this way provides considerable explanatory power (see the review in Lyons 2001).

${ }^{2}$ A volume effect is consistent with idiosyncratic portfolio rebalancing in response to news. Under rational expectations, given the immediate unbiased adjustment in price that it implies, one would not expect good news for the dollar to produce positive (or negative) order flow in the aggregate; i.e., one would not expect a relative increase in executed transactions initiated by dollar buyers. We return to this issue below when discussing potential simultaneity bias. 
We estimate a trading model that distinguishes three sources of exchange-rate variation. The first source mirrors traditional modelsmacro news that is impounded in price immediately and directly (i.e., with no role for order flow). The second source is the indirect effect of news via induced order flow. ${ }^{3}$ The third source is order flow unrelated to public news (such as that due to banks' changing risk tolerances, firms' changing hedging demands, or individuals' changing liquidity demands; see, e.g., Evans and Lyons 2002a). We find that for the $\mathrm{DM} / \$$ market, all three sources of exchange rate variation are significant. The flow of transacted orders between marketmakers (our measure of order flow) varies considerably with macro news flow, such that at least half of the effect of macro news on exchange rates is transmitted via order flow, the remainder being the direct effect of news. We also find that when news arrives, there is an increase in the relative importance of order flow in exchange rate determination, despite intuition from macro models to the contrary. Together, the two news channels account for about 30 percent of long-horizon price variance (from intraday estimates).

Though the literature linking exchange rates and news is well-developed, we are the first to our knowledge to use order flow to sort out the relationship. The existing literature has two branches: the first addresses the direction of exchange-rate changes (first moments) and the second, later branch addresses exchange-rate volatility (second moments). A common finding of the first branch is that directional effects from scheduled macro announcements are difficult to detect at the daily frequency because they are swamped by other factors affecting price. Intraday event studies find statistically significant effects, particularly for employment and money-supply announcements, but $\mathrm{R}^{2}$ statistics are generally low. ${ }^{4}$ The second, later branch of this literature-which focuses on

${ }^{3}$ That this channel might be operative is another reminder that order flow and demand are not one to one. To clarify, consider a simple counter-example. In the common-knowledge tradition of exchange rate economics, when positive public news arrives, demand increases, causing price to increase-without any flow of transacted orders occurring or needing to occur.

This is incompatible with demand and order flow being one to one: the demand shift occurs without the occurrence of order flow.

${ }^{4}$ See, for example, Cornell (1982), Engel and Frankel (1984), Hakkio and Pearce (1985), Ito and Roley (1987), Hardouvelis (1988), Ederington and Lee (1995), and Andersen et al. (2002). The latter paper is more successful at finding systematic first-moment effects from scheduled announcements. Note that explaining first moments within event windows for 
news effects on volatility is partly a response to the lack of strong news effects on first moments. ${ }^{5}$ This work finds that the largest changes in exchange rates are linked to the arrival of scheduled announcements. On the other hand, though major announcements dominate the volatility picture at release, their ability to account for overall volatility changes is less than that of systematic features such as ARCH and time-of-day effects (Andersen and Bollerslev 1998). ${ }^{6}$

Our paper departs from earlier work on macro news in two main ways. First, we consider a broader set of macro news events. Scheduled announcements account for about 10 percent of the macro news arrivals we obtain from the Reuters Money Market Headline News screen. (The median number of macro news arrivals per day in our sample is 11.) This allows us to test whether this wider set of news types affects the processes for transactions and returns in ways not examined previously. At the same time, including a broad set of news types requires a change in estimation strategy because it is not possible to measure ex-ante expectations for most of them (e.g., a report on the Headline News screen of an official stating that the trade deficit is unsustainable). This leads to the second of our main departures from earlier work on macro news: like Rigobon and Sack (2002), we depart from the event-study approach to measuring impact on asset prices and adopt instead an approach based on the state dependent heteroskedasticity. ${ }^{7}$ Specifically, we identify (via GMM) the relative importance of direct and indirect

scheduled announcements does not translate into high explanatory power over first moments generally: event windows for this type of macro news comprise a small fraction of the full time series. In this paper, the sample of macro news events is much broader than the set of scheduled announcements (addressed below).

${ }^{5}$ See, for example, Goodhart et al. (1993), DeGennaro and Shrieves (1997), and Andersen and Bollerslev (1998). See also the work on bond prices and announcements, e.g., Fleming and Remolona (1999), Balduzzi et al. (2001), Fleming (2002), and Green (2002). The latter two papers are especially relevant in that they use direct measures of order flow in fixed income markets. Green (2002), for example, finds evidence that asymmetric information increases following public macro announcements.

6 Accounting for volatility changes and accounting volatility levels of are not the same. For example, abnormal volatility in response to heightened news arrivals may dissipate rapidly, but that does not imply that trading induced by past news arrival cannot continue to contribute to normal volatility (a point we return to below).

${ }^{7}$ See the discussion in Rigobon and Sack (2002) comparing the merits of the event-study and heteroskedasticity approaches. Omitted variable bias in event-study analysis is simply a 
effects from news by allowing the variances of shocks to order flow and price to depend separately on the rate of news arrival. These second moment conditions identify our model and answer the central question before us, namely, whether order flow plays a role in transmitting news to exchange rates. This approach, as in Rigobon and Sack (2002), does not require measurement of news' unanticipated component; it requires the weaker assumption that one can distinguish periods in which the variance of macro news flow is relatively high. We use news arrivals for this purpose.

Why is news affecting exchange rates via order flow? Our preferred interpretation is that participants in this market are drawing different inferences from common macroeconomic data. Whether it is rational to do so is beyond the scope of this paper. But the phenomenon is certainly not limited to the FX market: think, for example, of differences in analyst forecasts of future stock market indices, despite access to common information about aggregate equity values (Harris and Raviv 1993).

The remainder of the paper is in four sections. Section 1 describes our data and presents some descriptive statistics. Section 2 presents daily analysis of the three sources of price adjustment. Section 3 presents intra-daily analysis of the three sources. Section 4 concludes.

\section{Data and Descriptive Statistics}

Our empirical strategy is two pronged, encompassing two data frequencies and two complementary approaches to how macro news is transmitted to exchange rates. The first approach applies at the daily frequency, the second at intraday frequencies (in our case, five-minute observations). Daily analysis of exchange rate variation is interesting because daily changes in nominal exchange rate are, to a first approximation, a martingale. Any empirical model that explains daily price increments is therefore relevant for explaining exchange rate levels at long horizons. This martingale property at the daily frequency does not apply to intraday prices, which exhibit mean reversion, as we shall show. The upshot is that disentangling different sources of daily exchange rate variation

manifestation of a point made above, namely, that specific effects are often swamped by other factors affecting price. 
provides a solid indication of decompositions at frequencies more familiar to macroeconomists (e.g., monthly). But daily analysis does not convey the rich intraday structure of news effects. Nor is it suited to addressing whether news makes order flow more or less important in exchange rate determination. For these we turn to intraday analysis.

Our order flow and price data are drawn from time-stamped, tick-by-tick transactions in the largest spot market $\mathrm{DM} /$ \$-ever a four-month period, May 1 to August 31, 1996 (full 24-hour trading day). The data source is the same as that in Evans (2002) and we refer readers there for additional detail. The transactions are from the Reuters Dealing 2000-1 system. At the time of our sample, Dealing 2000-1 was the most widely used electronic dealing system: according to Reuters, over 90 percent of the world's bilateral transactions between DM $/ \$$ marketmakers took place through the system. ${ }^{8}$ For every trade executed on D2000-1, our data set includes a time-stamped record of the transaction price and a bought/sold indicator. The bought/sold indicator allows us to sign trades for measuring order flow.

For our daily analysis, $\Delta p_{t}$ is the change in the DM transaction price for purchases of dollars from 5 pm BST (British Summer Time) on day t-1 to 5 pm BST on day t. ${ }^{9}$ When a purchase transaction does not occur precisely at $5 \mathrm{pm}$, we use the immediately preceding purchase price. Daily order flow $x_{t}$ is the difference between the number of trades initiated by dollar buyers and the number initiated by dollar sellers over the same time interval (in hundred thousands, negative sign denotes net dollar sales). ${ }^{10}$ For our

8 At the time of our sample, transactions between marketmakers accounted for about 75 percent of total trading in major spot markets. This 75 percent breaks into two transaction types-direct (bilateral) and brokered. Direct trading accounted for about 60 percent of trades between marketmakers and brokered trading accounted for about 40 percent. For more detail on the Reuters Dealing 2000-1 System see Lyons (2001) and Evans (2002).

${ }^{9}$ Using prices from purchase transactions (i.e., transactions at the ask) eliminates return reversals that would arise in prices that bounce randomly from bid to ask.

${ }^{10}$ In direct trading between marketmakers, orders sizes are standardized, so variation in size is much smaller than variation in the size of individual customer-marketmaker trades. Note too that using measures of order flow based on numbers of transactions rather than size is common in work on equity markets, even when both measures are available (see, e.g., Hasbrouck 1991). Our data set does include total dollar volume over our sample, which allows us to calculate an average trade size; we use this below to interpret the estimated coefficients. 
five-minute returns, which we denote $\Delta p_{i}$, we also use the immediately preceding transaction when no transaction occurs precisely at the five minute mark. (With roughly 1 million transactions per day, the preceding transaction is generally only seconds earlier.) Five-minute order flow $x_{i}$ is defined similarly to $x_{t}$ but over the five-minute interval matching $\Delta p_{i}$.

Our data on news arrivals come from the Reuter's Money Market Headline News screen (source: Olsen Associates). These screens are standard equipment on FX trading desks and are used for high frequency monitoring by non-marketmaker participants as well. Our daily frequency variable $A_{t}$ is the number of news arrivals relating to U.S. or German macroeconomics between 5:01 pm BST on day t-1 and $5 \mathrm{pm} \mathrm{BST}$ on day t. The five-minute analogue of $A_{t}$ is denoted $A_{i}$. The dummy variable $A_{i}$ takes the value of one if there was a news arrival (U.S. or German) during the previous five minutes. (We use a dummy variable approach in the five-minute data because there are very few instances of more than one news arrival during a single five-minute observation window.) In our fourmonth sample, there are 315 five-minute windows in which at least one news arrival occurs. Arrivals in the raw news data recorded after 20:00 hrs and before 6:30 (BST) are quite rare and typically refer to previous news events within the heart of the trading day. For this reason we do not include the few news arrivals that occur in this time interval in our sample.

As noted, our methodology allows us to consider a much wider set of macro news types. This is important because our four-month sample sharply constrains our ability to work with news arrivals on a fully disaggregated basis (i.e., by individual news types, such as Unemployment Claims). Though there is no ready measure ex-ante expectations for more than 80 percent of this full news set, there is a subset for which a commonly used measure of expectations exists, namely the subset of scheduled macro announcements (that measure being survey responses provided by Money Market Services and used extensively in foreign exchange event studies). We secured these survey data from Money Market Services so that we could measure innovations for this subset more accurately and compare our results from this subset to results from the full set of macro 
news events. This provides an indication of the statistical power gained by extending the news definition beyond the narrow definition for which the best expectation proxies exist. Another (partial) disaggregation for which our sample provides some statistical power is U.S. versus German news. Results for these two disaggregations are presented in the next section.

Table 1 presents descriptive statistics for the variables used in our daily analysis (upper panel) and intraday analysis (lower panel). For the daily analysis these variables include news flow $A_{t}$, price changes $\Delta p_{t}$, and order flow between marketmakers $x_{t}$. The median number of daily news arrivals is 11,8 of which pertain to Germany. As noted, these news events extend well beyond the scheduled announcements that are the focus of most past work. (The most important scheduled announcements for explaining changes in exchange rate volatility are employment, GDP, the trade balance, and durable goods; see Andersen and Bollerslev 1998.) Our intraday analysis includes a variable not included in the daily analysis, namely $n_{i}$, the total number of trades over each five-minute interval. This variable accounts for dependence on trading intensity in the intraday model, as we shall see. Note that intraday price changes display (negative) autocorrelation, but only at lag one. Thus, future price changes cannot be predicted from past changes beyond a five minute horizon-a-result confirmed by the ARMA model estimates in Evans 2002 (i.e., price changes follow an MA(1)). Order flow is much more persistent. For perspective, we note that on the day with the most news arrivals (28), the realization of $\left|\Delta p_{t}\right|$ was at the $73^{\text {rd }}$ percentile of its distribution, the realization of $\left|\Delta x_{t}\right|$ was at its $92^{\text {nd }}$ percentile, and the realization of trading intensity $n_{i}$ was at its $86^{\text {th }}$ percentile.

Figures 1 and 2 provide more perspective on the announcement data. Figure 1 shows the sample distribution for all news arrivals (both U.S. and German) by 30-minute interval. Figure 2 provides a list of the first twenty arrivals in the sample. These news events clearly extend well beyond scheduled announcements. (Including only the latter would leave many trading days in our sample without a single news event.) Note too that none of the news arrivals (in Figure 2 or in the whole sample) correspond to events like 'such and such official says the dollar-DM market was quite volatile this morning." This 
kind of endogeneity in the flow of news would be problematic for our empirical strategy, given its reliance on news-induced heteroskedasticity in returns. Note too the first of the listed news items: that the German bond market will close for public holiday. It is tempting to assert that this could not possibly affect order flow since it is perfectly anticipatable. But even in this case, as extreme as it is, it is not clear that there cannot be information content. Imagine a fixed-income portfolio manager in the U.S. that has been thinking about shifting into or out of bonds in Germany, but who might not have had this particular German holiday on his mind. The public news may induce him to trade right away, in advance of the closure, and the innovation in his demand (and others like him) can affect price. In short, this bit of information may not have been in the information sets of all the relevant participants. We prefer to let the data speak: if these macro news items are just noise then the rate of their arrival should not be correlated with trading activity or exchange rate volatility.

Whether news arrival is correlated with trading activity and volatility is addressed in Figure 3. It presents a scatter plot of the number of news arrivals per day $\left(A_{t}\right)$ against the daily variance of returns and order flow. To measure the two realized variances more precisely, we use a measure of integrated variance based on a five-minute sampling frequency. ${ }^{11}$ From the figure there is clearly a relationship: the variances of both returns and order flow are higher when the flow of macro news is higher. The positive link between the variance of returns and news flow is well documented in the existing literature. The positive link between the variance of order flow and news flow is new. Our daily model gives this positive link more structure, to which we turn in the next section.

As a final point regarding data, the major spot markets have recently undergone some institutional changes. Since the time of our sample in 1996, trading between marketmakers has migrated significantly from bilateral trading (the source of our data) to brokered trading over the EBS and Reuters Dealing 2000-2 systems (see BIS 2002). Does this render our analysis based on order flow obsolete? No, for two reasons. First, bilateral trading between marketmakers accounts for the lion's share of total trading through

${ }^{11}$ See the Appendix for details on these integrated variance measures. 
virtually all of the post Bretton Woods era. That the FX market is now more oriented toward brokered trading does not render the type of data we use here obsolete for understanding post Bretton Woods floating rates. Second, though it is true that the specific order flow data we use is now a smaller share of the total, this does not imply that order flow analysis is less useful going forward. Strategies for order flow measurement and capture will need to change (e.g., extracting it from electronic broker systems). But the role of order flow in conveying information, in theory and in practice, transcends market structure. The types of information that order flow conveys particularly types with persistent price effects are unlikely to change radically as the FX market changes over time. Put another way, the underlying information structure of this market has more to do with the properties of the asset being traded than it does with market structure per se. Order flow should continue to convey dispersed information that needs to be aggregated and subsequently impounded in price. The methodology we introduce here is more robust than a cursory look at market structure might suggest.

\section{Daily Analysis: Direct vs Indirect Effects from News}

Our daily analysis relies heavily on the portfolio shifts model of trading developed in Evans and Lyons (2002a). Accordingly, rather than review that model's details, our presentation focuses on ways this paper extends that earlier framework. We base our daily analysis on the portfolio shifts model because it serves three important purposes. First, the model clarifies how and why causation runs strictly from order flow to price. Within microstructure theory more broadly, this direction of causality is the norm (e.g., Glosten and Milgrom 1985 and Kyle 1985). Second, the model clarifies why price determination should depend most directly on a particular type of order flow, namely, the flow of orders between marketmakers. (This measure of flow is the most transparent to the marketmakers and therefore plays the most important role in updating their beliefs.) This feature of the model corresponds well to reality and produces estimable equations because this type of flow data is available (largely because this type of trading occurs electronically, unlike data on trades between marketmakers and the public). Third, the model provides underlying economics for why price effects from order flow should persist. The basic reason is 
that flow innovations provide signals about stochastic portfolio shifts (such as those due to changing hedging demands by a subset of agents). These portfolio shifts must be reabsorbed in equilibrium by the rest of the market, thereby inducing persistent portfolio balance effects on price.

This paper's extension of the portfolio shifts model introduces a macro news arrival whose implications for the exchange rate are not common knowledge. ${ }^{12}$ Specifically, the information in news has two components. The first component is a commonknowledge (or 'mean') part: all agents agree what the first part's impact on the exchange rate should be. (This will be the source of the direct effects on the exchange rate.) The second component is the part whose implication for the exchange rate is not common knowledge. Suppose, for example, that all agents do not have access to the same technology for transforming the macro news into an exchange rate forecast. The information in this second part is thus dispersed throughout the economy and for price-setting marketmakers to aggregate it, they need to learn from the public trades that are induced by it. ${ }^{13}$

The model produces three basic channels through which information affects prices. The first is the traditional direct channel for public information: the common-knowledge part of macro news is reflected instantaneously in price, a process that does not rely in any way on the flow of transacted orders. The second is the channel for the non-common-knowledge part of macro news: information in the induced order flow is impounded in price as it is realized. The third is the channel for information in other types of order flow, i.e., order flow unrelated to macro news flow (such as trades motivated by shocks to individuals' hedging demands or shocks to banks' effective risk aversions due to capital constraints, etc.).

The model leads to the following empirical specification for daily price changes and order flow:

${ }^{12}$ An earlier version of this paper provides formal treatment of this change in information structure. Though the change is fundamental, it does not involve a fundamental change in the analytics, so we omit it here to conserve space. A copy of that earlier version is available at haas.berkeley.edu/ lyons/macronewsold.pdf.

${ }^{13}$ How do marketmakers respond to scheduled announcements in practice? For the major announcements (which represent a small subset of our data), bank economists typically produce a forecast of the announcement's value (e.g., the employment report) that is distributed to that bank's marketmakers that morning. The sheet with the forecast will often include a prediction for the exchange rate impact, but marketmakers are left to their own judgment regarding how to respond. Our best reading from observing the process is that some price adjustment does indeed occur rapidly across the market, with little apparent role for flow. But announcements often induce follow-on trading, some of which comes later the same day from customers whose trading 


$$
\begin{aligned}
\Delta p_{t} & =\alpha x_{t}+\xi_{t}+\kappa_{t} \\
x_{t} & =e_{t}+\eta_{t}
\end{aligned}
$$

where $\Delta p_{t}$ is the change in the exchange rate $(\mathrm{DM} / \$)$ from the end day $\mathrm{t}-1$ to end day $\mathrm{t}$ and $x_{t}$ is order flow between marketmakers realized over the same period. The parameter $\alpha$ captures the price impact of order flow, i.e., it reflects the information content of order flow. Prices and order flow are subject to four shocks representing different sources of information hitting the market. These shocks are mean zero, mutually uncorrelated, and serially uncorrelated. The $\xi_{t}$ and $\kappa_{t}$ shocks represent information that is impounded in price directly. $\xi_{t}$ is the common knowledge effect of macro news arrivals on the exchange rate. $\kappa_{t}$ represents other information directly impounded in prices, i.e., information that is unrelated to both order flow or macro news events. Order flow is driven by the $e_{t}$ and $\eta_{t}$ shocks. The $e_{t}$ shocks represent order flow effects from macro news arrivals the non-common-knowledge effect of the news. Shocks to order flow that are unrelated to macro news (i.e., portfolio shifts arising from other sources such as changing risk tolerances or hedging) are represented by the $\eta_{t}$ shocks.

The estimation strategy in our daily analysis relies on identification through conditional heteroskedasticity. The key conditioning variable is the number of macro news arrivals between the end of day $\mathrm{t}-1$ and the end of day $\mathrm{t}, A_{t}$. We allow the variance of the $\xi_{t}$ and $e_{t}$ shocks to increase with the number of news arrivals:

$$
\operatorname{Var}\left(e_{t}\right)=\sigma\left(A_{t}\right) \quad \text { and } \quad \operatorname{Var}\left(\xi_{t}\right)=\omega\left(A_{t}\right)
$$

where $\sigma(0)=\omega(0)=0$, with $\sigma^{\prime}($.$) \geq and \omega^{\prime}() \geq$.0 . This specification implies that neither the $\xi_{t}$ nor the $e_{t}$ shocks affect prices on days when there are no news

response is not instantaneous. It is these (unforecastable) customer trading responses that the model is designed to capture. 
arrivals. The shocks $\kappa_{t}$ and $\eta_{t}$ are independent of news, so their variances are unrelated to $A_{t}$. We assume these variances are constant:

$$
\operatorname{Var}\left(\kappa_{t}\right)=s_{\kappa} \text { and } \operatorname{Var}\left(\eta_{t}\right)=s_{\eta}
$$

To estimate the model described in equations (1) -(4) we specify linear forms for the variance functions $\sigma($.$) and \omega($.$) , which we later subject to diagnostic testing. The$ parameters of these functions along with $s_{\kappa}$ and $s_{\eta}$ are estimated by the Generalized Method of Moments (GMM), with conditions on second moments playing the central role in identification. (Estimation details are described in the Appendix.) The answer to the central question of this paper-does order flow help to transmit macro news to exchange rates-amounts to a test of whether the parameter $\sigma$ is positive and significant. The relative importance of the direct and indirect news channels can be determined from the relative sizes of the estimated parameters $\omega$ and $\sigma$. (The importance of the indirect effect on price from the latter also depends on the magnitude of the estimated price impact coefficient $\alpha$.)

To the above specification we add one last feature: room for contemporaneous returns to enter the order flow equation (2). An effect of returns on order flow is not optimal within the motivating theory, but as an empirical matter, estimating an overly restrictive model is not necessary. Specifically, we enrich the model in equations (1) and (2) to the following:

$$
\begin{aligned}
\Delta p_{t} & =\alpha x_{t}^{*}+\xi_{t}+\kappa_{t} \\
x_{t} & =x_{t}^{*}+x_{t}^{+} \\
x_{t}^{*} & =e_{t}+\eta_{t} \\
x_{t}^{+} & =\phi \Delta p_{t}
\end{aligned}
$$


This specification includes an additional component of order flow, $x_{t}^{+}$, which is driven by contemporaneous returns. The parameter $\phi$ is easily estimated within our GMM framework.

To illustrate how identification through heteroskedasticity is achieved in the model, consider how the two key parameters $\alpha$ and $\phi$ relate to the covariance between price changes and order flow. Equations (5)-(8) imply the following expression for that covariance:

$$
\operatorname{Cov}(\Delta \mathrm{p}, \mathrm{x})=\mathrm{a}(1+\alpha \phi) \operatorname{Var}(\mathrm{e}+\eta)+\phi \operatorname{Var}(\xi+\kappa)
$$

Identification is achieved by considering how the moments in the data change across states. In particular, the arrival of macro news affects both terms on the right-hand side: from equation (3), both $\operatorname{Var}(\mathrm{e})$ and $\operatorname{Var}(\xi)$ increase, where the former is the indirect order-flow effect on price and the latter is the direct effect on price. The resulting change in $\operatorname{Cov}(\Delta \mathrm{p}, \mathrm{x})$ depends on the values of $\alpha$ and $\phi$. While this link alone is insufficient to identify $\alpha$ and $\phi$, these parameters also determine how macro news affects the variance of price changes and order flow (see appendix). Taken together, data on changes in $\operatorname{Cov}(\Delta \mathrm{p}, \mathrm{x}), \operatorname{Var}(\Delta \mathrm{p})$, and $\operatorname{Var}(\mathrm{x})$ that are induced by daily variation in news arrival $\mathrm{A}_{\mathrm{t}}$ (through $\mathrm{A}_{\mathrm{t}}$ 's impact on $\operatorname{Var}(\mathrm{e})$ and $\operatorname{Var}(\xi)$ ) are sufficient to identify all the parameters of the model. ${ }^{14}$

There are at least two reasons why contemporaneous returns might enter the daily order flow equation. ${ }^{15}$ The first is aggregation bias. As we show in the Appendix, when the intraday relationship between order flow and returns has an extended intertemporal structure, then the simple sums that daily data represent cannot capture the relationship

14 The covariance equation above also clarifies why positive values of $\alpha$ or $\phi$ could in principle account for the positive unconditional covariance between price changes and order flow found in the data. The model estimates allow us to determine whether this covariance arises because order flow has a positive price impact or because price changes feedback positively into order flow. We also estimated a version of the model where total order flow $\mathrm{x}$ is included in equation (5), as opposed to the non-feedback-driven flow $x^{*}$. Estimates from this alternative specification are not substantially different from those we report in Table 2.

${ }^{15}$ At the daily frequency, order flow and lagged returns in our data are uncorrelated, so we do not lose generality by including only contemporaneous returns in the order flow equation. 
fully. In this case, time-aggregated order flow $x_{t}$ is not quite the right measure to include as a regressor in equation (1). As a result, joint estimation of equations (5) through (8) will produce a non-zero $\phi$. The second reason why contemporaneous returns might enter the daily order flow equation is intraday feedback trading. ${ }^{16}$ (In daily data, intraday feedback trading would appear contemporaneous.) If intraday returns do not follow a martingale then individuals might rationally choose a feedback strategy. For example, if intraday returns exhibit reversals then negative feedback trading would be a natural response.

Though our specification in equations (5)-(8) address reverse causality (from returns to order flow), there is another causality issue we have not yet addressed: Can positive macro news cause an increase in both order flow and price (with no causality from order flow to price)? This hypothesis seems plausible at first blush. It is, however, inconsistent with rational expectations. The reason is because- $u n d e r$ rational expectations public information is impounded in price instantaneously. At the new price, which fully impounds the public information, there is no longer motivation for dollar buying relative to dollar selling. ${ }^{17}$ The change in price level may induce trading at the new price (i.e., unsigned volume). But on average good news for the dollar will not produce positive order flow in the aggregate at the new price (a relative increase in transactions initiated by dollar buyers). In our model, this restriction imposed by rational expectations implies that the news-driven return shock $\xi_{t}$ and the order flow shocks $e_{t}$ and $\eta_{t}$ are orthogonal.

\footnotetext{
${ }^{16}$ That feedback trading is even feasible on average, given that marketmakers are on both sides of every transaction in our data, is not obvious. Why wouldn't marketmakers anticipate these inter-marketmaker feedback trades and attempt to undo the anticipatable effects on their positions from the incoming orders? They would. But in equilibrium they would be unable to do so by trading with other marketmakers: somebody has to take the other side of these trades. For inter-marketmaker trading to be positive feedback on average, the trades of non-marketmakers would have to be negative feedback on average. This is possible, but not very satisfying intellectually. Osler (2002) reports evidence on the types of orders non-marketmakers actually submit. For evidence on the currency transaction flows of institutional investors, a specific class of non-marketmaker, see Froot and Ramadorai (2002).

${ }^{17}$ One way to produce this non-causal correlation between order flow and price changes is if marketmakers are able to execute dollar purchases against other marketmakers before price adjusts to the public information. But this would require irrationality on the part of the quoting
} 
The theory on which we base our empirical models is subtler. Part of the public news maps directly into price, as in the traditional story (the shock $\xi_{t}$ ). But if to some degree market participants are drawing different inferences from common macro data, then price-setting marketmakers need to clear the market by determining the inferences of others (which they cannot know a priori). How do they learn them? The answer from microstructure theory is that they learn from the sequence of submitted orders over time. In this case, price instantaneously adjusts to the marketmaker's rational expectation of the market's interpretation, and then goes through a period of gradual adjustment caused by the sequence of transacted orders.

\section{Daily Results}

We turn to the empirical model in equations (5) through (8) for sorting out the direct versus indirect (via order flow) effects of news. The full empirical model embeds six parameters, $\alpha, \omega, \sigma, \phi, s_{\kappa}$, and $s_{\eta}$. The parameter $\alpha$ captures the price impact of order flow. For the central question of this paperhow is macro news transmitted to exchange rates the key parameters are $\omega$ and $\sigma . \omega$ governs the direct effect of news on price: the greater the number of news arrivals $A_{t}$ the higher the variance of this component of daily returns. $\sigma$ governs the direct effect of news on order flow: the greater the number of news arrivals $A_{t}$ the higher the variance of this component of daily order flow. ${ }^{18}$ The variance $s_{\kappa}$ reflects the component of daily returns not explained by order flow or news. The variance $s_{\eta}$ reflects the component of daily order flow not explained by news.

marketmaker: by not instantaneously impounding the public information in price he is permitting trades at "stale" prices, clearly a losing proposition.

${ }^{18}$ Though the derivation for model equation (1) does not call for order flow lags, whether they are relevant empirically is a legitimate robustness concern. The daily analysis in Evans and Lyons (2002a) shows, however, that order flow lags are insignificant when included in this specification. Indeed, our order flow measure shows no persistence in daily data, nor do daily returns, so we are not omitting any variables that a non-structural VAR approach would identify as significant. 
Table 2 reports GMM parameter estimates together with standard errors calculated from the asymptotic covariance matrix (allowing for heteroskedasticity). ${ }^{19}$ The table reports estimates for specifications using the flow of all news arrivals lumped together (labeled All News) and also with the U.S. and German news introduced separately. In both specifications the estimate of the price-impact parameter $\alpha$ is positive, as the theory predicts, and statistically significant. (Its size corresponds to a price impact of roughly 50 basis points per $\$ 1$ billion in order flow.) The parameter $\phi$, which captures the contemporaneous effect of returns on order flow, is negative and significant. Recall that we offered two reasons why a negative relationship might exist here: temporal aggregation bias and negative feedback trading (on average) by marketmakers. We address these hypotheses in more detail in our intraday analysis. (At this stage, let us simply add that it is comforting that these results regarding news effects are robust to including a role for $\phi$. The overall news results are essentially unchanged when we restrict $\phi$ equal to zero.) With all news arrivals lumped together, both of the key parameters $\omega$ and $\sigma$ are significant and correctly signed (positive), implying that both direct and indirect effects of news on price are present. When U.S. and German news events are introduced separately (last column), both of the $\omega$ estimates are significant and correctly signed (positive). Also, the effect of German news on order flow volatility $\left(\sigma_{g}\right)$ is positive and significant. The effect of U.S. news is of similar size but is not significant at the five percent level. (Recall that the median number of daily German news arrivals is nearly three times that for U.S. news arrivals.) In both specifications, the two (unconstrained) variance parameters $s_{\kappa}$ and $s_{\eta}$ are quite significant. The next rows of the table report Wald statistics for various parameter restrictions. The first two of these rows show that in the unrestricted model (i.e., with U.S. and German news separated), the null that the direct and indirect news channels are insignificant are strongly rejected. From the third row, the restriction that

${ }^{19}$ Though not reported, we estimated the model allowing the price-impact parameter $\alpha$ to vary linearly with the number of announcements: the coefficient on the incremental announcement effect was positive but not significant. We also tested whether announcement effects on the variance of order flow might be non-linear (by modeling the variance of $e_{t}$ as $\sigma A_{t}^{\gamma}$ ), but found no evidence of this either. 
both of the $\omega$ and $\sigma$ coefficient pairs are equal cannot be rejected, which provides support for the restricted specification in the All News column.

Important summary statistics are provided in the final rows of Table 2 . The three rows labeled with $R_{\Delta p}^{2}$ present the fraction of total variance in price attributable on average to the direct and indirect effects of news. The indirect channel (through order flow) is roughly twice the size of the direct effect: 19 percent versus 10 percent, respectively. ${ }^{20}$ The final row presents the P-value for the test that the direct effect is larger than the indirect effect. In the restricted (All News) model, the hypothesis that the direct effect is larger is rejected. (Recall that the restrictions on that model are not rejected.)

To summarize, we do indeed find that order flow helps transmit macro news to exchange rates. Roughly 20 percent of the daily movements in spot rates can be linked to macroeconomic news through the indirect order-flow channel. Through the direct (traditional) channel, macro news accounts for about 10 percent of daily price movements. ${ }^{21}$ Given rejection of the test for whether $R_{\Delta p}^{2}($ direct $)>R_{\Delta p}^{2}($ indirect $)$, we conclude that at least half of the effect of macro news on the exchange rate is transmitted via order flow. Finally, let us provide a big-picture accounting from these point estimates. The analysis in Evans and Lyons (2002a) shows that about 60 percent of daily DM/\$ price variation is due to order flow and about 40 percent is due to other factors. The results in Table 2 shed light on both of these pieces. They suggest that the 60 percent from order flow breaks into 20 percent that is induced by macro news and 40 percent that is not news

${ }^{20}$ Given that much of the past work on news and exchange rates implicitly assumes that the indirect channel is not present, we also estimate our daily model with the (rejected) restriction that $\sigma$ equals zero. We find that the $R_{\Delta p}^{2}$ from the direct channel rises above 10 percent, but only to 13.6 percent, i.e., it does not rise to anywhere near the 29 percent we find for both channels. This may help explain why the explanatory power of news in our model is relatively high (see too the analysis below of the subset of scheduled announcements).

${ }^{21}$ Noise in our measurement of news arrivals may bias down our estimates of the total percentage of price variance from news flow, but it is not obvious why this should bias our estimates of the relative importance of the direct and indirect channels. For this reason, we place most significance on our results regarding relative importance. With respect to the possible biasing down of the total percentage, note that our results are positive in this respect (i.e., we find a large percentage relative to existing literature); eliminating the bias, if it exists, would only make our result more striking. 
induced. The 40 percent due to other factors in that earlier work breaks into 10 percent from the direct effect of macro news and 30 percent that remains unaccounted for.

\section{$\underline{\text { Robustness }}$}

In this subsection we consider several potential robustness issues. First, might our broad definition of macro news account for the relatively large share of volatility due to public news arrival (29 percent)? To address this we turn to the subset of our news data that represents scheduled macroeconomic announcements, the subset for which we have ex-ante survey expectations for measuring announcement innovations. We focus on four U.S. announcements in particular, all of which are consistently among the most important in past event studies: Non Farm Payroll, Durable Goods, Trade Balance, and Unemployment Claims. ${ }^{22}$ We create a set of standardized forecast errors using the sample standard deviations of the measured innovations. Then, for each day in the sample we construct an index $A_{t}$ equal to the sum of the absolute standardized forecast errors. Then we re-estimate our model in Table 2 using this alternative measure of macro news flow. The results from this version of the model are in Appendix Table 1.

The results are similar in some ways to those in Table 2, but quite dissimilar in other ways. They are similar in that the feedback trading parameter $\phi$ is still negative and still significant. The key parameters $\omega$ and $\sigma$ are also still positive and significant (at the 4 and 6 percent levels, respectively). The big difference is in the bottom line: the variance ratios are 0.014 for the direct channel and 0.028 for the indirect channel (aggregated news case), implying that these scheduled announcements account for only about 4 percent of total exchange rate variance. Thus, using this more limited measure of news accounts for far less of the daily price variance than the full set of Reuter's Money Market Headline News. This is consistent with

\footnotetext{
${ }^{22}$ We select these announcements to give the "scheduled announcement" model a greater chance of success. In fact, results from including all the scheduled U.S. announcements for which survey expectations are available are even poorer than the results we report, presumably because most of these other announcements are insignificant for exchange rates (as shown in earlier work). For German announcements, there is little empirical basis for selecting the more significant announcement types so we include all those announcements for which we have survey expectations.
} 
past work, which shows that scheduled announcements account for less that 10 percent of daily price variance. Thus, it does appear that our broad definition of macro news can account for our finding that a large share of volatility is due to public news arrival.

Appendix Table 1 also speaks to a related robustness check: might our definition of macro news account for the indirect channel (via order flow) being twice as important for exchange rate variance as the direct channel (i.e., 19 of 29 percent)? Note that the ratio of indirect to direct effects in Appendix Table 1 remains about the same as those in Table 2, namely 2 to1, suggesting that the relative importance of the indirect channel is not due to our definition of news.

As a third type of robustness check we turn to regression analysis to examine the sources and form of heteroskedasticity. We consider (i) the extent to which news flow can account for the conditional variance of returns and order flow and (ii) whether the linear specifications of the variance functions $\sigma\left(A_{t}\right)$ and $\omega\left(A_{t}\right)$ in our baseline model are warranted. As described in the Appendix, we test for news-related heteroskedasticity by regressing the daily conditional variance of returns on a constant and the daily news flow $A_{t}$. We perform the same regression for the daily conditional variance of order flow. We find a significant direct effect of news on the conditional variance of prices (see Appendix Table 2). We also find a significant direct effect of news on the conditional variance of order flow. The first of these two results is consistent with existing literature. The second is new, though, and quite important to the economics underlying our model. (Both results are consistent with the visual evidence in the scatter plots in Figure 3.) Regarding potential non-linearity in the news flow effects, we find no evidence that squared newsflow terms should be included in the regression.

To summarize the robustness results above, we find that our inclusive definition of macro news is important for explaining a large fraction of exchange rate variation. Our news definition is also important for understanding why the model explains so much exchange rate variation relative to existing literature. In contrast, our news definition does not appear to be important for the result that the indirect macro news channel is at least as important as the direct channel. Our regression analysis finds a strong effect of news flow 
on order flow volatility: the order flow process is not orthogonal to public news, as simple rational expectations models would predict. Finally, our regression results support the linear specifications we adopt in our GMM model and corroborate that both direct and indirect price effects from news are present.

\section{Intraday Analysis: Direct vs Indirect Effects from News}

Our second approach complements the daily analysis above by examining intraday data, specifically five-minute data. At this ultra-high frequency, we have sufficient power to estimate both returns and order flow as state-dependent processes. These processes

allow the arrival of news to affect price dynamics quite generally. Also, our intraday analysis allows us to estimate the percentage of price variation at different horizons that comes from order flow shocks, and how that percentage changes with news arrival. This is important for answering whether order flow plays a larger or smaller role in exchange rate determination when news arrives. Finally, unlike our daily analysis, which permitted only unconditional inferences, our intraday analysis allows us to draw conclusions about news, order flow, and price conditional on trading intensity and price-impact horizon.

Our intraday model, designed for use in five-minute data, extends the empirical model in Evans (2002). This model takes the form:

$$
\begin{aligned}
\Delta p_{i} & =B(L) v_{i}+\varepsilon_{i} \\
x_{i} & =\widetilde{C}(L) v_{i}
\end{aligned}
$$

where now we use the subscript $\mathrm{i}$ to denote the five-minute frequency. Here, $v_{i}$ represents dispersed information shocks, i.e., bits of information that are first manifested in order flow and then subsequently impounded in price. The dynamic responses of prices and order flow to these dispersed information shocks are determined by the lag polynomials $B(L)$ and $\widetilde{C}(L)$. The other term in the price equation corresponds to common- 
knowledge news $\varepsilon_{i}$. The $v_{i}$ and $\varepsilon_{i}$ shocks are mutually independent and serially uncorrelated.

There are two key identifying assumptions in this model: rational expectations and imperfect substitutability across different-currency assets. To understand the first, note that we require orthogonality between the common-knowledge news shock $\varepsilon_{i}$ and the dispersed information shock $v_{i}$. This orthogonality derives from the rational expectations restriction that common-knowledge news shocks are impounded fully and instantaneously in price (see the discussion of causality within the daily model). The second identifying assumption maintains that all order flow $x_{i}$ represents dispersed information. Imperfect substitutability together with rational expectations is sufficient to ensure this: with imperfect substitutability (i.e., demand for foreign exchange that is imperfectly elastic), all order flow conveys price-relevant information since all order flow requires price adjustment to achieve market clearing. ${ }^{23}$ (The rational expectations assumption ensures this information is dispersed rather than public.) Based on this specification in equation (10) we shall address whether our intraday estimates are consistent with an aggregationbias explanation for the negative estimates of $\phi$ (reported in Table 2).

In ultra-high frequency data, such as the five-minute data we examine in this section, it is important to account for subtleties in the timing of dispersed information shocks relative to the timing of order flow. In particular, the first event in the foreign exchange trading process is a desire to transact on the part of the non-marketmaker customer. This is not the order flow we measure, however. The trades between marketmakers measured by $x_{i}$ are temporally downstream from the initial customer order. If, for example, some information conveyed by customer orders is impounded in price when customer orders are executed, then price is adjusting before trades between marketmakers are induced, despite the fact that order flow the customer orderis driving the price change (see Evans 2001, pages 48-49). It is important to account for these initial stages of price

${ }^{23}$ With perfect substitutability, in contrast, order flow can have price irrelevant components. It is perhaps best to think of the dispersed information shock $v_{i}$ in equation (10) as a composite shock that includes any information relating to narrowly defined fundamentals as well as information relating to portfolio balance effects on price. 
adjustment. Figure 4 provides additional perspective. The bottom line is that even when causality is running wholly from order flow to price, the temporal link between our order flow measure $x_{i}$ and price changes will involve both leads and lags.

To develop an estimable model, we proceed in two steps. First, we assume that the lag polynomial in the order flow equation, $\widetilde{C}(L)$, can be written as $L^{m} C(L)$ where $C(L)^{-1}$ exists and follows an autoregressive process. $m$ denotes the number of (fiveminute) periods between the first effects on price from a typical customer order and its subsequent effect on order flow between marketmarkers, $x_{i}$. With these assumptions we can rewrite equation (9) as

$$
\Delta p_{i}=D(L) x_{i}+\varepsilon_{i},
$$

where $D(L)=B(L) L^{-m} C(L)^{-1}$. The polynomial $D(L)$ may take many forms depending on the dynamic responses of price and order flow to dispersed information shocks. Notice though that if $m>0$, as illustrated in Figure 4, $D(L)$ should contain both leads and lags (because the polynomials $B(L)$ and $C(L)^{-1}$ contain only non-negative powers of $L$ ). We follow Evans (2002) in using a six-term polynomial: $D(L)=d_{1} L^{-4}+d_{2} L^{-3}+\ldots+d_{6} L$ as our basic specification. Similarly, we find that the dynamics of order flow are well characterized if $C(L)^{-1}$ is an $\mathrm{AR}(10)$. In both cases, coefficient estimates on further leads/lags for price changes, and lags for order flow, are not statistically significant when more general specifications are estimated (see Evans 2002 for further diagnostics supporting these specifications). The specification for $D(L)$ implies that a customer order can begin to have an impact on price approximately 20 minutes before it affects order flow between marketmakers (i.e., $m=4$ ).

The second step is to test whether the lag polynomials and the error variances are dependent on macro news having arrived. Evans (2002) reports strong evidence of dependence on trading intensity, $n_{i}$, measured as the number of transactions in observation window $i$. (Including trading intensity as a state variable is important for accommo- 
dating the pronounced time dependence in volatility documented by Andersen and Bollerslev 1998.) Here we extend the analysis by including macro news arrival as an additional state variable. Specifically, we construct dummy variables $A_{i}^{*}$ and $A_{i}$ that take the value of one if there was a news arrival (either U.S. or German) during the previous 15 or 5 minutes respectively. ${ }^{24}$ The results in Appendix Table 3 shows that there is strong evidence for state-dependence in the return equation polynomial $D(L)$, with respect to both $A_{i}^{*}$ and $n_{i}$, but not the order flow polynomial $C(L)^{-1}$. There is also strong evidence of heteroskedasticity related to $A_{i}$ and $n_{i}$ in the error variances.

These results point to the need to incorporate state-dependence into our intraday model. To this end, we consider an extension of (9) where $D(L)$ is replaced by $D\left(L, n_{i}, A_{i}^{*}\right)$, a state-dependent 6 'th order polynomial:

$$
D\left(L, n, A^{*}\right)=d_{1}\left(n, A^{*}\right) L^{-4}+d_{2}\left(n, A^{*}\right) L^{-3}+\ldots .+d_{6}\left(n, A^{*}\right) L
$$

with state-dependent coefficients $d_{j}\left(n, A^{*}\right)$. Thus, $d_{6}\left(n, A^{*}=1\right)$ is the coefficient on lagged order flow when news arrived in the past 15 minutes, and trade intensity equals $\mathrm{n}$. We also allow for heteroskedasticity in the error variances, $\operatorname{Var}\left(\varepsilon_{i}\right)=\Sigma_{\varepsilon}\left(n_{i}, A_{i}\right)$ and $\operatorname{Var}\left(v_{i}\right)=\Sigma_{v}\left(n_{i}, A_{i}\right)$. State-dependence in the coefficients and variances is modeled as:

$$
\begin{gathered}
d_{j}\left(n, A^{*}\right)=d_{j}\left(0, A^{*}\right) \exp (-n / \gamma)+d_{j}\left(\infty, A^{*}\right)(1-\exp (-n / \gamma)) \\
\Sigma_{j}(n, A)=\Sigma_{j}(0, A) \exp (-n / \gamma)+\Sigma_{j}(\infty, A)(1-\exp (-n / \gamma))
\end{gathered}
$$

where $d_{j}(0,0), d_{j}(\infty, 0), \Sigma_{j}(0,0)$, and $\Sigma_{j}(\infty, 0)$ are the parameters to be estimated for observations without a news arrival, and $d_{j}(0,1), d_{j}(\infty, 1), \Sigma_{j}(0,1)$, and $\Sigma_{j}(\infty, 1)$ when

${ }^{24}$ As noted, we a dummy variable approach here because there are very few instances where there is more than one news arrival during a single 5-minute observation window. Note too that for our intraday analysis there is no scope for using the MMS-measured expected values 
there is a news arrival. Although these functional forms are somewhat specialized with respect to variations in trading intensity, they do not restrict how the flow of news affects price and order flow dynamics. Nor do they appear unduly restrictive when we subject our model to specification tests below.

\section{Intraday Results}

Table 3 presents GMM estimates of the intraday model. One measure of the importance of state-dependence in the price change dynamics is the sum of the order flow coefficients $D\left(1, n, A^{*}\right)$. This measures the long run impact of order flow on the price level. The estimated $D\left(1, n, A^{*}\right)$ varies considerably with both trading intensity and macro news flow. This is consistent with the findings of our state-dependence tests. It also accords with the non-parametric evidence on state-dependence in hourly price change data reported in Evans and Lyons (2002b). The variation in the estimates of $D\left(1, n, A^{*}\right)$ also underlines how the analysis of intraday data brings greater resolution of the study of return and order flow dynamics.

Before studying the implications of our estimates, we examine a number of diagnostic tests (see Appendix Table 4). First, we examine the null hypothesis of no statedependence in $D\left(1, n, A^{*}\right)$. Consistent with our earlier results, this hypothesis is strongly rejected with respect to trade intensity and macro news flow. Second, we consider LMtype tests for mis-specification in the estimated $d_{j}\left(n, A^{*}\right)$ and $\Sigma_{j}(n, A)$ functions. None of these tests are statistically significant suggesting that the estimated model has captured well the state-dependence related to trading intensity and news flow. Third, we examine whether the model captures all the heteroskedasticity in the data. Here we find evidence of some residual ARCH effects. So, while the model does appear to capture the statedependent dynamics of prices and order flow with respect to trading intensity and news flow, it does not account for all the sources of heteroskedasticity. As a final diagnostic, we examine whether the estimated intraday model can account for the negative estimates

for scheduled announcements (to measure announcement innovations) because even for monthly announcements there are only four forecast errors in our sample for each announcement type. 
of $\phi$ found in the daily model. Under the null of our intraday model, time-aggregated (i.e., daily) order flow $x_{t}$ is only approximately equal to the correct measure of order flow that should be present in equation (1). Moreover, as the appendix shows, estimates of the intraday model imply that the approximation error is negatively correlated with daily price changes. In other words, the negative estimates of $\phi$ can arise through timeaggregation of the price and order flow dynamics that are described by our intraday model. $^{25}$

We now turn of the point of this section: How is the information in macro news transmitted to prices? To answer this question we use the GMM estimates to compute the fraction of price variance attributable to dispersed information across different market states. Specifically, our estimates allow us to write price changes as:

$$
\Delta p_{i}=B\left(L, n_{i}, A_{i}^{*}\right) v_{i}+\varepsilon_{i}
$$

where. $B\left(L, n, A^{*}\right)=D\left(L, n, A^{*}\right) L^{4} C(L)$. Using this equation, we can compute the fraction of the variance in a k-period price change due to $v_{i}$ shocks for a given level of trade intensity and news flow. Table 4 shows that this fraction increases with trade intensity and horizon (as in Evans 2002). More importantly, however, there is a marked difference in the contribution according to whether or not news arrives. For all trade intensities and horizons, dispersed information contributes more to the variance of price changes when news has arrived. Indeed, comparison of the first and second panels shows that order flow accounts for two to three times as much price variance when news has arrived. Thus, order flow is more important in exchange rate determination when news arrives, not less. The p-values for the hypothesis that there is no increase in the ratio,

${ }^{25}$ It is noteworthy that the process followed by exchange rates essentially rules out positive feedback trading that is also rational. To understand why, recall from Table 1 that there is no autocorrelation in returns beyond the first five-minute lag (negative in that case, and arising primarily due to dispersion across marketmakers' quotes at a given time, not as a median-price phenomenon). Given that transactions are costly, and given that there is no positive autocorrelation in returns, a positive feedback trading strategy would clearly be a negative-profit strategy. 
shown in the lower panel, are all small, particularly at the 5-minute horizon and in the limit as the horizon approaches infinity.

\section{Conclusions}

This paper extends the literature on exchange rates and public news in three main ways. First, our analysis is the first to address the presence and importance of an indirect channel through which public news affects exchange rates. Second, methodologically we depart from existing literature on exchange rates and public news by using heteroskedasticity-based identification, a la Rigobon and Sack (2002), rather than the event-study approach. Third, our methodology accommodates a much wider set of news events than the scheduled macro announcements that are the focus of event studies.

To address the indirect channel, we test whether macroeconomic news is transmitted to exchange rates via transactions and if so, what share occurs via transactions versus the traditional direct channel. Our model distinguishes three sources of exchange-rate variation. The first source mirrors traditional models public news that is impounded in price immediately and directly (i.e., with no role for order flow). The second source is an indirect effect of public news that operates via induced order flow. The third source of exchange rate variation is order flow unrelated to public news arrival. No previous work has disentangled these three sources empirically.

Using DM/\$ data from 1996, we find that all three sources of price variation are significant. Our point estimates at the daily frequency imply that about two thirds of the price effect from macro news is transmitted via order flow, with the remaining one third being the direct impounding of news in price. Unconditionally, the total effect accounts for about 30 percent of long-horizon exchange rate variance. We reject the null that the

direct channel is the more important, implying that the indirect channel accounts for at least half of the effect of macro news on the DM/ $\$$ rate. ${ }^{26}$ These daily results are consistent with those at the five-minute frequency. In particular, our five-minute results in Table 
4 show that when news arrives there is a 100-200 percent increase in the importance of order flow in price determination. This is inconsistent with the natural prior that order flow should be less important when public news arrives. These intraday results apply consistently when conditioning on both trading intensity and price-impact horizon.

Why, one might ask, does this paper find that roughly 30 percent of total volatility comes from news effects whereas past work finds that news effects account for less than 10 percent? We offer three possible reasons. First, we consider a much wider set of macro news arrivals. When we used the more common, and more limited set of scheduled announcements (for which survey expectations are readily available) we found they could account for only about 5 percent of total volatility. Second, we adopt a heteroskedasticity approach that does not rely on measuring ex-ante expectations for each of these news arrivals (c.f., the event-study approach). Third, we use a less restrictive model in the sense that we allow for an indirect channel and we allow flow responses to dispersed information to persist over extended periods. Event studies impose window lengths that constrain response times, typically less than one hour in intraday analysis. (In practice, response times for some participants surely extend beyond an hour.) This constraint might appear rather loose: past work finds that volatility changes from announcements dissipate quickly (e.g., half-lives less than an hour). But volatility does not go to zero when shocks to volatility dissipate; it settles back to a (statistical) mean. Volatility being at its mean does not imply that last hour's news is irrelevant for current trading. Rather, participants' macro views evolve continuously and trades induced by those evolving views can hit the market over extended periods. ${ }^{27}$

It would be heroic indeed for us to assert that causality between order flow and exchange rates is strictly one directional. It is, almost surely, two directional, at least

\footnotetext{
our analysis.

${ }^{27}$ Carlson (2002), for example, finds that in response to a public macro announcement, liquidity in an electronic interbank trading system (Reuters 2000-2) remained significantly below normal (and below its ex ante state) for about 2 hours. Even if average effects from news are reflected in prices quickly, as in Andersen and Bollerslev (1998) and Cheung and Chinn (2001), this does not imply that total effects are reflected quickly. Average effects may correspond to the
}

${ }^{26}$ Whether this result generalizes to less actively traded currencies is beyond the scope of 
under some circumstances. ${ }^{28}$ That said, as a theoretical matter the portfolio shifts model underlying our analysis provides a clear formalization of one-directional causality, even in the face of public information. As an empirical matter, we allowed for the potential presence of reverse causality but found no evidence supporting the most commonly offered form, namely positive-feedback trading. Moreover, existing micro evidence of causality running from order flow to prices in stock, bond, and FX markets is so strong that there is no compelling basis for believing that causality runs wholly or even largely in reverse (for micro evidence in stocks and bonds see the survey by Madhavan 2000). In our judgment an indirect channel through which news affects exchange rates has indeed been identified.

direct, or rational expectations channel, which one would expect to be reflected more quickly than indirect, order-flow mediated effects.

${ }^{28}$ One possible channel of reverse causality is when exchange rate changes are large enough to induce distress at some institutions, causing them to sell into falling markets (and vice versa) for risk management purposes. 


\section{References}

Andersen, T., and T. Bollerslev (1998), Deutsche mark-dollar volatility: Intraday activity patterns, macroeconomic announcements, and longer run dependencies, Journal of Finance, 53: 219-265.

Andersen, T., T. Bollerslev, F. Diebold, C. Vega (2002), Micro effects of macro announcements: Real-time price discovery in foreign exchange, NBER Working Paper 8959, May.

Andersen, T., T. Bollerslev, F. Diebold, and P. Labys (2001), The distribution of realized exchange rate volatility, Journal of the American Statistical Association, 96: 4255.

Balduzzi, P., E. Elton, and C. Green (2001), Economic news and bond prices, Journal of Financial and Quantitative Analysis, forthcoming.

Bank for International Settlements-BIS (2002), Central bank survey of foreign exchange market activity in April 2001. Publication of the Monetary and Economics Department, BIS (at www.bis.org).

Carlson, J., (2002), One minute in the life of the DM/\$: Public information in an electronic market, typescript, Purdue University, August.

Cheung, Y., and M. Chinn, (2001), Currency traders and exchange rate dynamics: A survey of the U.S. market, Journal of International Money and Finance, 20: 439471 .

Chinn, M. (1991), Some linear and non-linear thoughts on exchange rates, Journal of International Money and Finance, 10: 214-230.

Cornell, B. (1982), Money supply announcements, interest rates, and foreign exchange, Journal of International Money and Finance, 1: 201-208.

DeGennaro, R., and R. Shrieves (1997), Public information releases, private information arrival, and volatility in the foreign exchange market, Journal of Empirical Finance, 4: 295-315.

Ederington, L., and J. Lee (1995), The short-run dynamics of price adjustment to new information, Journal of Financial and Quantitative Analysis, 30: 117-134. 
Engel, C., and J. Frankel (1984), Why interest rates react to money announcements: An answer from the foreign exchange market, Journal of Monetary Economics, 13: 31-39.

Evans, M. (2001), FX trading and exchange rate dynamics, NBER Working Paper 8116, February.

Evans, M. (2002), FX trading and exchange rate dynamics, Journal of Finance, 57: 24052448.

Evans, M., and R. Lyons (2002a), Order flow and exchange rate dynamics, Journal of Political Economy, 110: 170-180.

Evans, M., and R. Lyons (2002b), Time-varying liquidity in foreign exchange, Journal of Monetary Economics, 49: 1025-1051.

Fleming, M., (2002), Price discovery in the U.S. treasury market: The impact of order flow and liquidity on the yield curve, typescript, New York Federal Reserve Bank, September.

Fleming, M., and E. Remolona (1999), Price formation and liquidity in the U.S. treasury market, Journal of Finance, 54: 1901-1915.

Flood, R., and A. Rose (1995), Fixing exchange rates: A virtual quest for fundamentals, Journal of Monetary Economics 36, 3-37.

Frankel, J., and K. Froot (1990), Chartists, fundamentalists, and trading in the foreign exchange market, American Economic Review, 80: 181-185.

Frankel, J., and A. Rose (1995), Empirical research on nominal exchange rates, in G. Grossman and K. Rogoff (eds.), Handbook of International Economics, Elsevier Science: Amsterdam, 1689-1729.

Froot, K., and T. Ramadorai (2002), Currency returns, institutional investor flows, and exchange rate fundamentals, NBER Working Paper 9101, August.

Glesjer, H. (1969), A new test for heteroskedasticity, Journal of the American Statistical Association, 64: 316-323.

Glosten, L., and P. Milgrom (1985), Bid, ask, and transaction prices in a specialist market with heterogeneously informed agents, Journal of Financial Economics, 14: 71100. 
Goodhart, C., S. Hall, S. Henry, and B. Pesaran (1993), News effects in a high-frequency model of the sterling-dollar exchange rate, Journal of Applied Econometrics, 8: 113.

Green, C., (2002), Economic news and the impact of trading on bond prices, typescript, Emory University, May, Journal of Finance, forthcoming.

Greene, William H. (1997), Econometric Analysis, Prentice Hall.

Grossman, S., and J. Stiglitz (1980), On the impossibility of informationally efficient markets, American Economic Review, 70: 393-408.

Hakkio C., and D. Pearce (1985), The reaction of exchange rates to economic news, Economic Inquiry, 23: 621-635.

Hardouvelis, G. (1988), Economic news, exchange rates, and interest rates, Journal of International Money and Finance, 7: 23-25.

Harris, M., and A. Raviv (1993), Differences of opinion make a horse race, Review of Financial Studies, 6: 473-506.

Hasbrouck, J. (1991), Measuring the information content of stock trades, Journal of Finance, 46: 179-207.

Hasbrouck, J., and D. Seppi (2001), Common factors in prices, order flows, and liquidity, Journal of Financial Economics, 59: 383-411.

Isard, P. (1995), Exchange Rate Economics, Cambridge University Press: Cambridge, UK.

Ito, T., and V. Roley (1987), News from the U.S. and Japan: Which moves the yen/dollar exchange rate? Journal of Monetary Economics, 19: 255-277.

Jones, C., G. Kaul, and M. Lipson (1994), Transactions, volume, and volatility, Review of Financial Studies, 7: 631-651.

Jones, C., and M. Lipson (1999), Execution costs of institutional equity orders, Journal of Financial Intermediation, 8: 123-140.

Kandel, E., and N. Pearson (1995), Differential interpretation of public signals and trade in speculative markets, Journal of Political Economy, 103: 831-872.

Killeen, W., R. Lyons, and M. Moore (2001), Fixed versus flexible: Lessons from EMS order flow, NBER Working Paper 8491, September. 
Kyle, A. (1985), Continuous auctions and insider trading, Econometrica, 53:1315-35.

Lyons, R. (2001), The Microstructure Approach to Exchange Rates, MIT Press, published December (chapters at www.haas.berkeley.edu/ lyons).

Madhavan, A. (2000), Market microstructure:A survey, Journal of Financial Markets, 3:205-258.

Mark, N. (1995), Exchange rates and fundamentals: Evidence on long-horizon predictability, American Economic Review, 85: 201-218.

Meese, R., and K. Rogoff (1983a), Empirical exchange rate models of the seventies, Journal of International Economics, 14: 3-24.

Meese, R., and K. Rogoff (1983b), The out-of-sample failure of empirical exchange rate models, in J. Frenkel (ed.), Exchange Rate and International Macroeconomics, University of Chicago Press: Chicago.

Newey, W., and K. West (1987), A simple positive semi-definite, heteroskedasticity and autocorrelation consistent covariance matrix, Econometrica, 55: 703-708.

Osler, C. (2002), Currency orders and exchange-rate dynamics: An explanation for the predictive success of technical analysis, Journal of Finance, forthcoming.

Payne, R. (1999), Informed trade in spot foreign exchange markets: An empirical investigation, typescript, London School of Economics, January.

Rigobon, R., and B. Sack, (2002), The impact of monetary policy on asset prices, NBER Working Paper 8794, February.

Rime, D. (2000), Private or public information in foreign exchange markets? An empirical analysis, typescript, University of Oslo, March. 


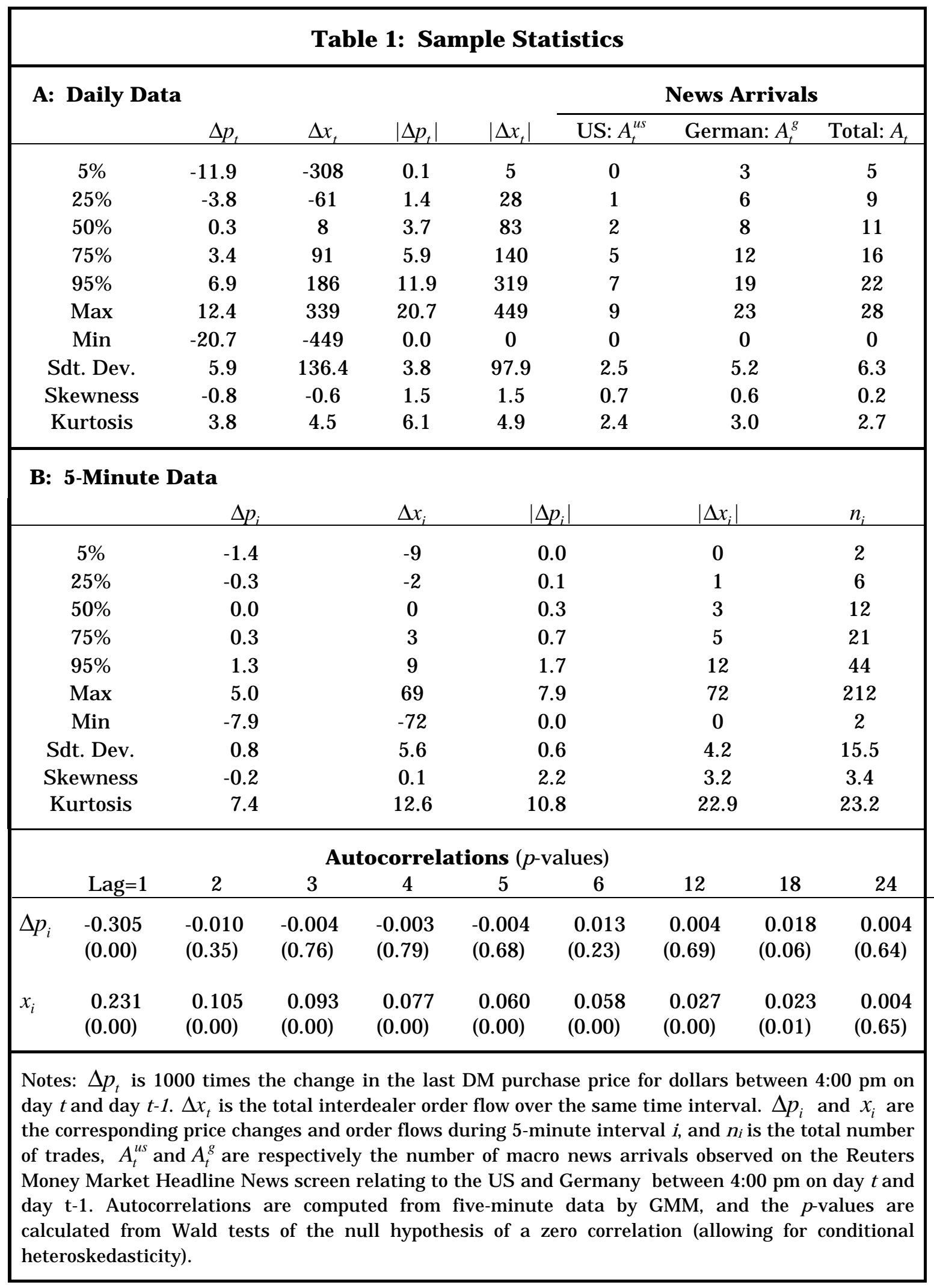




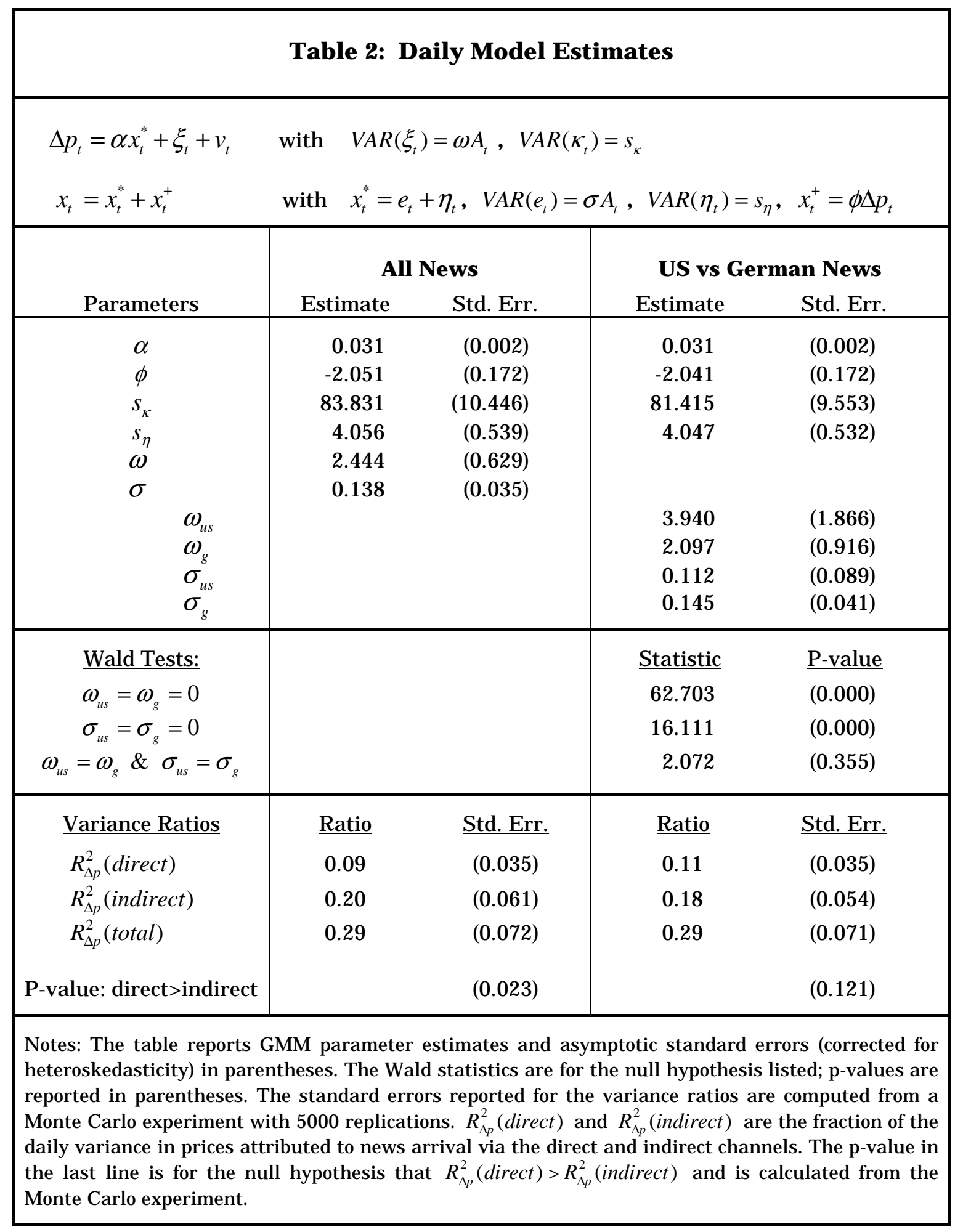




\section{Table 3: Intraday Model Estimates (GMM)}

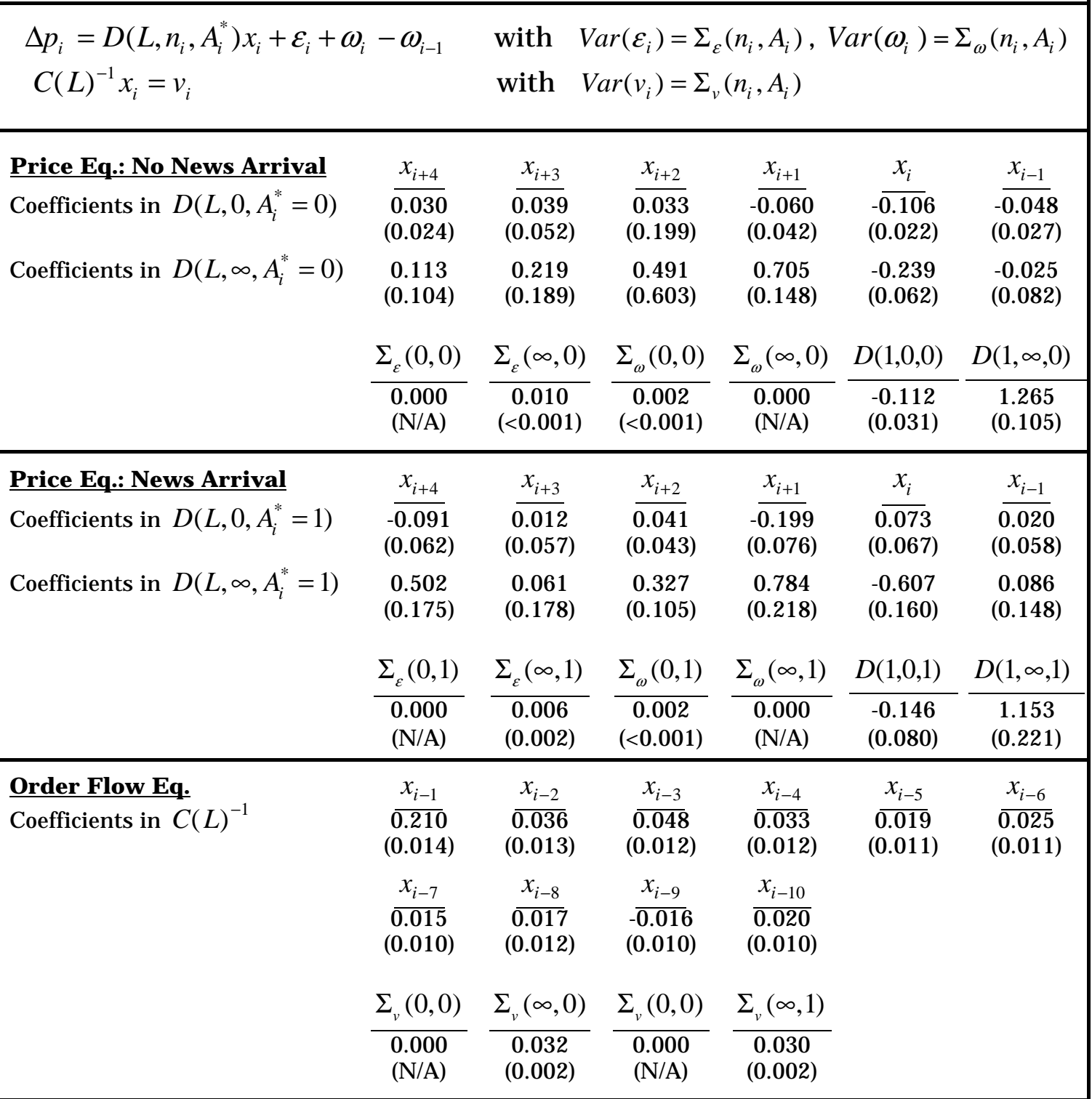

Notes: GMM estimates with asymptotic standard errors in parenthesis corrected for conditional heteroskedasticity and an MA(1) error term. (Coefficients and standard errors in the first two panels are multiplied by 100.) The state-dependent polynomial in the price equation is $D\left(L, n_{i}, A_{i}^{*}\right)=$ $d_{1}\left(n_{i}, A_{i}^{*}\right) L^{-4}+d_{2}\left(n_{i}, A_{i}^{*}\right) L^{-3}+\ldots .+d_{6}\left(n_{i}, A_{i}^{*}\right) L$ where $A_{i}^{*}$ is a dummy variable equal to one if there was a macro news arrival during the previous 15-minutes (i.e. 3 observation windows). State-dependency in the coefficients and variances is modeled as $d_{i}\left(n_{i}, A_{i}^{*}\right)=d_{i}\left(0, A_{i}^{*}\right) \exp \left(-n_{i} / \gamma\right)+$ $d_{j}\left(\infty, A_{i}^{*}\right)\left(1-\exp \left(-n_{i} / \gamma\right)\right)$, and $\Sigma_{j}\left(n_{i}, \lambda\right)=\Sigma_{j}\left(0, A_{i}\right) \exp \left(-n_{i} / \gamma\right)+\Sigma_{j}\left(\infty, A_{i}\right)\left(1-\exp \left(-n_{i} / \gamma\right)\right) \quad$ where $\gamma=100$, and $A_{i}$ is a dummy variable equal to one if there was a news arrival during the previous 5mintues. 
Table 4: Percentage Price Variance From Order Flow Shocks

\begin{tabular}{|cccccc}
\hline News Arrival & \multicolumn{5}{c}{ Horizon (minutes) } \\
& 5 & 30 & 60 & 120 & $\infty$ \\
\hline Trade intensity $\mathrm{n}$ & & & & \\
& 5.03 & 10.49 & 11.73 & 12.99 & 13.35 \\
& $(1.47)$ & $(5.44)$ & $(6.89)$ & $(8.54)$ & $(9.06)$ \\
& 9.87 & 17.97 & 19.26 & 20.50 & 20.84 \\
& $(2.59)$ & $(8.27)$ & $(9.88)$ & $(11.48)$ & $(11.94)$ \\
& 15.83 & 25.51 & 26.62 & 27.63 & 27.91 \\
& $(4.12)$ & $(10.87)$ & $(12.52)$ & $(14.09)$ & $(14.52)$
\end{tabular}

\section{No News Arrival}

\begin{tabular}{|c|c|c|c|c|c|}
\hline \multicolumn{6}{|c|}{ Horizon (minutes) } \\
\hline & 5 & 30 & 60 & 120 & $\infty$ \\
\hline \multicolumn{6}{|c|}{ Trade intensity $n$} \\
\hline 10 & $\begin{array}{c}1.45 \\
(1.17)\end{array}$ & $\begin{array}{c}2.63 \\
(2.72)\end{array}$ & $\begin{array}{c}2.53 \\
(3.43)\end{array}$ & $\begin{array}{c}2.41 \\
(4.34)\end{array}$ & $\begin{array}{c}2.37 \\
(0.52)\end{array}$ \\
\hline 20 & $\begin{array}{c}3.63 \\
(1.27)\end{array}$ & $\begin{array}{c}7.23 \\
(2.71)\end{array}$ & $\begin{array}{c}7.70 \\
(3.14)\end{array}$ & $\begin{array}{c}8.18 \\
(3.59)\end{array}$ & $\begin{array}{c}8.32 \\
(0.77)\end{array}$ \\
\hline 30 & $\begin{array}{c}6.54 \\
(1.58)\end{array}$ & $\begin{array}{l}13.36 \\
(3.32)\end{array}$ & $\begin{array}{l}14.46 \\
(3.64)\end{array}$ & $\begin{array}{l}15.48 \\
(3.94)\end{array}$ & $\begin{array}{l}15.76 \\
(1.30)\end{array}$ \\
\hline \multicolumn{6}{|c|}{ P-values: No increase in variance ratio } \\
\hline \multicolumn{6}{|c|}{ Horizon (minutes) } \\
\hline & 5 & 30 & 60 & 120 & $\infty$ \\
\hline \multicolumn{6}{|c|}{$\underline{\text { Trade intensity } n}$} \\
\hline 10 & 0.02 & 0.04 & 0.06 & 0.08 & 0.01 \\
\hline 20 & 0.00 & 0.02 & 0.03 & 0.05 & 0.01 \\
\hline 30 & 0.00 & 0.03 & 0.05 & 0.08 & 0.02 \\
\hline \multicolumn{6}{|c|}{$\begin{array}{l}\text { Notes: Estimated from five-minute data (model in Table } 3 \text { ). The upper two panels report the } \\
\text { percentage of price variance over various horizons due to order flow shocks, given trade intensity } n \text {, } \\
\text { with and without concurrent news arrival. (From Table } 1 \text {, the median number of trades n per five- } \\
\text { minute interval is } 12 \text { and the } 75^{\text {th }} \text { percentile is } 21 . \text { ) The standard errors reported in parenthesis in } \\
\text { the upper panels, and p-values shown in the lower panel are calculated from } 5000 \text { Monte Carlo } \\
\text { draws from the estimated asymptotic distribution of the GMM estimates. }\end{array}$} \\
\hline
\end{tabular}


Figure 1: Sample Distribution of News Arrivals

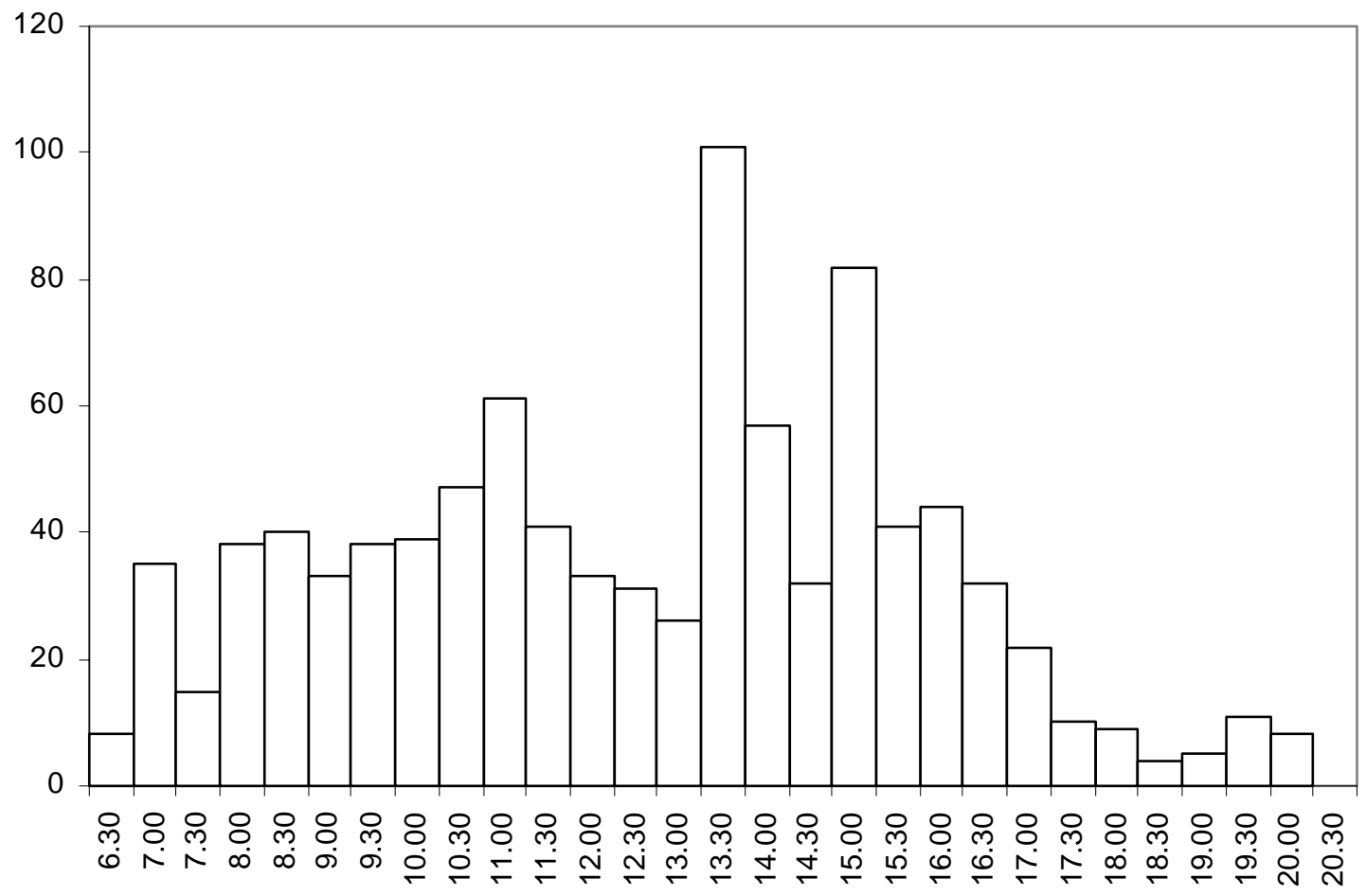

Notes: Distribution of all news arrivals by 30 minute interval starting at the interval centered at 6:30 BST and ending at the interval centered at 20:00 BST. Sample: May 1 to August 31, 1996. Data on news arrivals are from the Reuters Money Market Headline News screen. 


\section{Figure 2: Macro News Sample}

\begin{tabular}{cll} 
Date & \multicolumn{1}{c}{ Time } & \multicolumn{1}{c}{ News } \\
\hline 05/01/96 & $6: 00: 20$ & GERMAN BOND MARKET CLOSES FOR PUBLIC HOLIDAY \\
05/01/96 & $13: 05: 22$ & MARCH U.S. LEADING INDICATORS SHOW ECONOMY EASING \\
05/01/96 & $14: 00: 50$ & U.S. MARCH CONSTRUCTI ON SPENDING ROSE 3.1 PCT \\
05/01/96 & $14: 10: 14$ & MARCH U.S. CONSTRUCTION SPENDING REBOUNDS STRONGLY \\
05/02/96 & $6: 05: 18$ & GERMAN MARCH I MPORT PRICES CLIMB 0.3 PCT M/M \\
05/02/96 & $8: 33: 10$ & BUNDESBANK DOES NOT PLAN NEWS CONFERENCE TODAY \\
05/02/96 & $9: 48: 20$ & GERMAN CALL MONEY FALLS BACK TO 3.30/40 PCT \\
05/02/96 & $10: 50: 08$ & BUNDESBANK LEAVES INTEREST RATES UNCHANGED \\
05/02/96 & $10: 51: 56$ & GERMAN MARCH INDUSTRIAL OUTPUT DATA DUE 1130 GMT \\
05/02/96 & $12: 30: 40$ & U.S. J OBLESS CLAIMS FELL IN LATEST WEEK \\
05/02/96 & $12: 31: 00$ & U.S. Q1 1996 REAL GDP ROSE 2.8 PCT \\
05/02/96 & $14: 00: 30$ & U.S. MARCH FACTORY ORDERS ROSE 1.5 PCT \\
05/02/96 & $14: 34: 06$ & BUNDESBANK STEERING MARK EVEN LOWER-ANALYSTS \\
05/02/96 & $15: 01: 54$ & U.S. Q1 GDP SURGE SEEN J UST A BLIP IN MODEST TREND \\
05/02/96 & $15: 10: 32$ & GERMAN EMPLOYER TO OPPOSE ANTI-WAGE DUMPING LAW \\
05/03/96 & $9: 56: 32$ & GERMAN CALL MONEY EASES SLIGHTLY AHEAD OF WEEKEND \\
05/03/96 & $12: 30: 38$ & U.S. APRIL NON-FARM PAYROLLS ROSE 2,000 \\
05/03/96 & $12: 31: 00$ & U.S. MARCH PERSONAL INCOME ROSE 0.5 PCT \\
05/03/96 & $12: 38: 44$ & U.S. J OBLESS RATE LOWER BUT LABOR MARKET LOOKS WEAK \\
05/03/96 & $13: 42: 16$ & MARCH US INCOME DATA SHOW MODEST GROWTH, INFLATION \\
\hline
\end{tabular}

Notes: The figure shows the first 20 macro news arrivals in our sample (May 1 to August 31, 1996). 
Figure 3: Daily Price and Order Flow Volatility

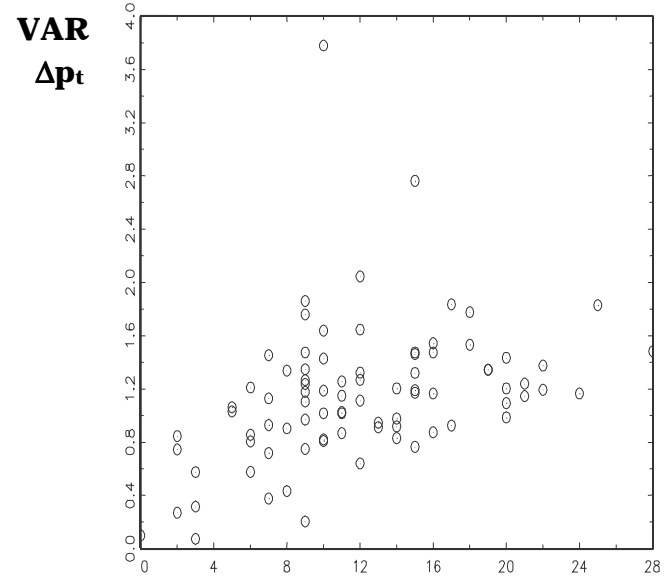

\#News Arrivals At

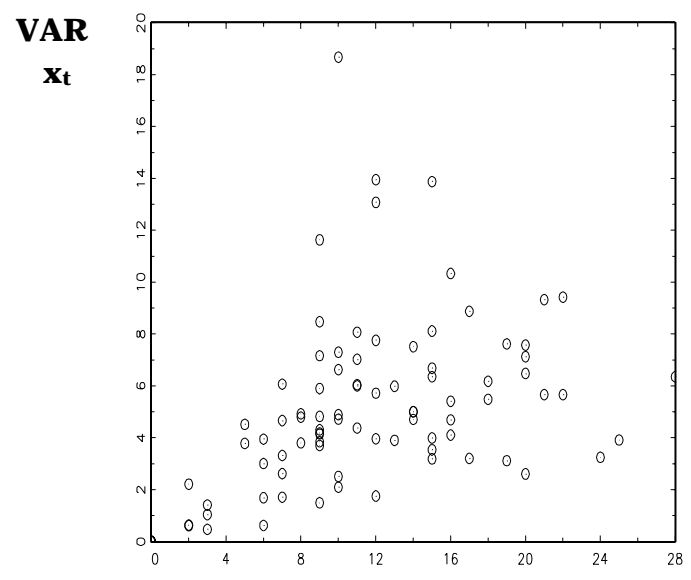

\#News Arrivals At

Notes: Daily data from May 1 to August 31, 1996. Data on news arrivals $A_{t}$ are from the Reuters Money Market Headline News screen. Daily realized variances for $\Delta \mathrm{p}_{\mathrm{t}}$ and $\mathrm{x}_{\mathrm{t}}$ are integrated variance measures based on a five-minute sampling frequency (Andersen et al. 2001). 
Figure 4: Time-line of Information F low at Ultra-High Frequencies

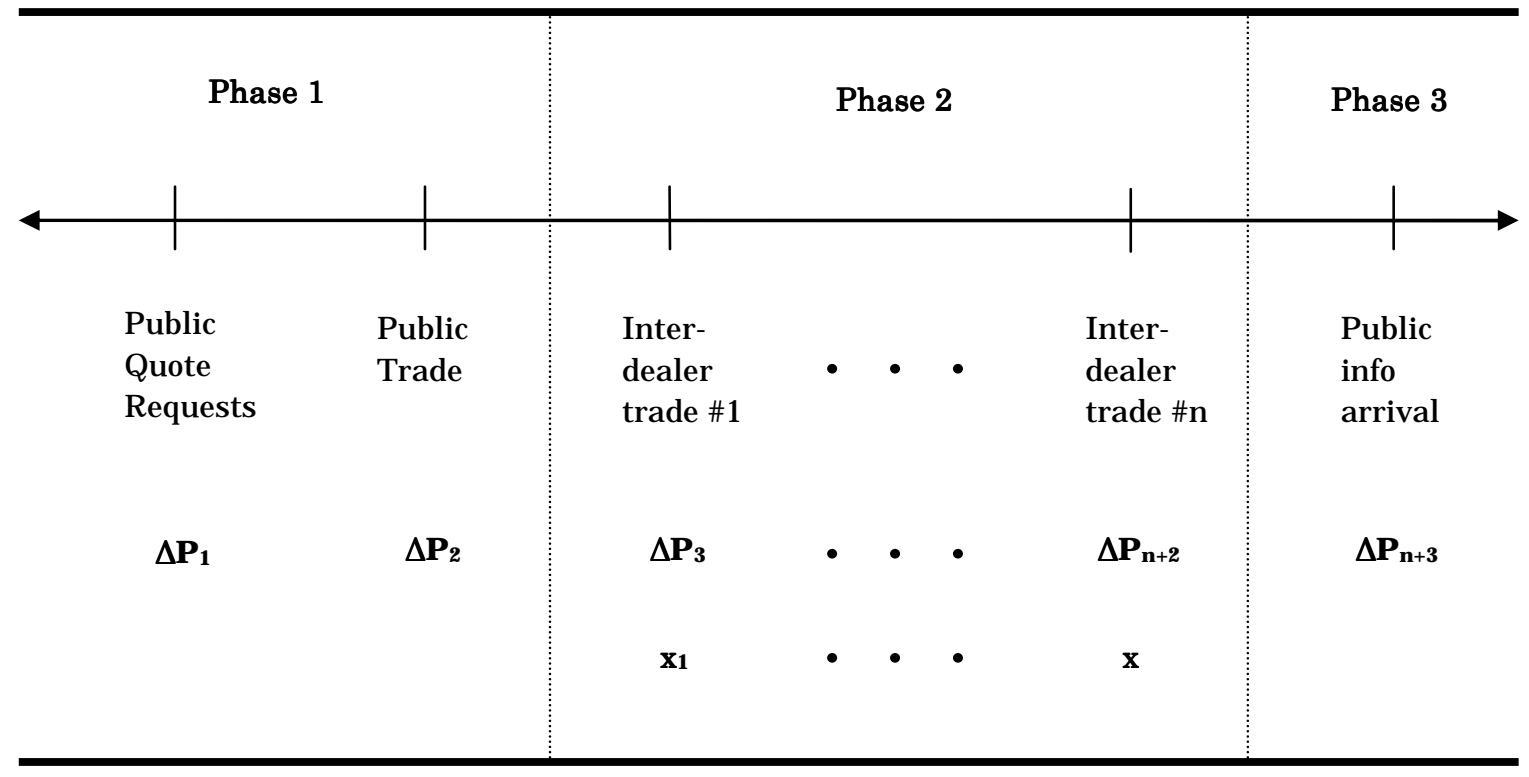

Notes: The response of price to order flow in ultra-high frequency data takes place as a series of increments that can be split into three phases. In the first, price is responding to public order flow $\left(\Delta \mathrm{P}_{1}\right.$ and $\left.\Delta \mathrm{P}_{2}\right)$, but before any trade between marketmakers (dealers) is realized. In the second phase, inter dealer order flows $\mathrm{x}_{\mathrm{i}}$ induced by the public order become the causal driver of additional price adjustment. The third phase includes any price changes due to subsequent public news that is correlated with the initial public trade (i.e., for which the initial public trade provides a signal). Jones and Lipson (1999) provide a nice discussion of the first of these price changes $\Delta \mathrm{P}_{1}$ : When customers call various banks for quotes, often these banks know something about whether the trade will be a buy or sell. So even those banks who do not receive the ultimate order have learned something about the trade before it is executed. Some of this information becomes impounded in price before the trade is realized. Evans (2002) provides analysis of the second of these price changes $\Delta \mathrm{P}_{2}$ (see especially pages 48-49): price adjusts to public order flow upon its execution, which occurs before the induced interdealer order flows. For detail on the phase-2 causal link between rounds of (hot potato) interdealer order flow and prices $\Delta \mathrm{P}_{3}$ through $\Delta \mathrm{P}_{\mathrm{n}+2}$, see Lyons (1997). 


\section{Appendix}

\section{Daily Data}

The reduced form of the model presented in (5) - (8) is:

$$
\begin{aligned}
\Delta p_{t} & =\alpha\left(e_{t}+\eta_{t}\right)+\xi_{t}+\kappa_{t} \\
x_{t} & =(1+\phi \alpha)\left(e_{t}+\eta_{t}\right)+\phi\left(\xi_{t}+v_{t}\right),
\end{aligned}
$$

where $\operatorname{Var}\left(\xi_{t}\right)=\omega A_{t}, \operatorname{Var}\left(\kappa_{t}\right)=s_{\kappa}, \operatorname{Var}\left(e_{t}\right)=\sigma A_{t}$, and $\operatorname{Var}\left(\eta_{t}\right)=s_{\eta}$. For the model where $A_{t}$ identifies all the news items in day $t, \omega$ and $\sigma$ are parameters. In the model where we separate US and German news items, $A_{t}^{\prime}=\left[A_{t}^{u s}, A_{t}^{g}\right], \omega=\left[\omega_{u s}, \omega_{g}\right]$ and $\sigma=\left[\sigma_{u s}, \sigma_{g}\right]$. To find the GMM estimates, we first find the variances and covariance for price changes and order flow implied by the equations above:

$$
\begin{aligned}
\operatorname{Var}\left(x_{t}\right) & =(1+\phi \alpha)^{2}\left(\sigma A_{t}+s_{\eta}\right)+\phi\left(\omega A_{t}+s_{\kappa}\right), \\
\operatorname{Var}\left(\Delta p_{t}\right) & =\alpha^{2}\left(\sigma A_{t}+s_{\eta}\right)+\left(\omega A_{t}+s_{\kappa}\right), \\
\operatorname{Cov}\left(x_{t}, \Delta p_{t}\right) & =(1+\phi \alpha) \alpha\left(\sigma A_{t}+s_{\eta}\right)+\phi\left(\omega A_{t}+s_{\kappa}\right) .
\end{aligned}
$$

Next, we construct empirical counterparts to these theoretical moments in the form of the integrated variances and covariance from the five-minute data:

$$
\mathcal{V}\left(\Delta p_{t}\right)=\sum_{i=1}^{288} \Delta p_{i t}^{2}, \quad \mathcal{V}\left(x_{t}\right)=\sum_{i=1}^{288} x_{i t}^{2}, \quad \text { and } \mathcal{C} \mathcal{V}\left(x_{t}, \Delta p_{t}\right)=\sum_{i=1}^{288}\left(\Delta p_{i t} x_{i t}\right)
$$

where the subscript "it" denotes the $i^{\prime}$ th. 5-minute observation on day $t$. The variables $\mathcal{V}\left(\Delta p_{t}\right), \mathcal{V}\left(x_{t}\right)$ and $\mathcal{C} \mathcal{V}\left(x_{t}, \Delta p_{t}\right)$ measure the realized volatility in price changes and order flow that, under suitable conditions, provide us with unbiased and highly efficient estimates of actual volatility (see, Andersen, Bollerslev, Diebold, and Labys 2001). [V $\left(\Delta p_{t}\right)$ and $\mathcal{V}\left(x_{t}\right)$ are plotted in Figure 3.] 
Table 2 reports GMM estimates based on the following set of moment conditions:

$$
\begin{aligned}
0 & =E\left[\left\{\mathcal{V}\left(\Delta p_{t}\right)-\operatorname{Var}\left(\Delta p_{t}\right)\right\} \otimes \mathcal{Z}_{t}\right], \\
0 & =E\left[\left\{\mathcal{V}\left(x_{t}\right)-\operatorname{Var}\left(x_{t}\right)\right\} \otimes \mathcal{Z}_{t}\right], \\
0 & =E\left[\left\{\mathcal{C V}\left(x_{t}, \Delta p_{t}\right)-\operatorname{Cov}\left(x_{t}, \Delta p_{t}\right)\right\} \otimes \mathcal{Z}_{t}\right], \\
0 & =E\left[\left(\Delta p_{t}-\frac{\alpha}{1+\alpha \phi} x_{t}\right)\left(x_{t}-\phi \Delta p_{t}\right)\right],
\end{aligned}
$$

where $\mathcal{Z}_{t}$ is a vector of instruments. The first three conditions imply that the difference between realized volatility any the (co)variance implied by the model is uncorrelated with each instrument. The fourth condition follows from the fact that shocks to the price equation, $\xi_{t}+\kappa_{t}$, are uncorrelated with $x_{t}^{*}=e_{t}+\eta_{t}$. In the case of the All News model, we use a constant and $A_{t}$ as instruments, and when US and German news are separated we use a constant, $A_{t}^{u s}$, and $A_{t}^{g}$.

The ratios reported in the lower panel of Table 2 are computed as

$$
\begin{aligned}
R_{\Delta p}^{2}(\text { direct }) & =\frac{\operatorname{Var}_{T}\left(\xi_{t}+\kappa_{t}\right)}{\operatorname{Var}_{T}\left(\Delta p_{t}\right)} R_{\xi}^{2}, \\
R_{\Delta p}^{2}(\text { indirect }) & =\frac{\hat{\alpha}^{2} \operatorname{Var}_{T}\left(x_{t}^{*}\right)}{\operatorname{Var}_{T}\left(\Delta p_{t}\right)} R_{e}^{2}, \\
R_{\Delta p}^{2}(\text { total }) & =R_{\Delta p}^{2}(\text { direct })+R_{\Delta p}^{2}(\text { indirect }),
\end{aligned}
$$

where $\operatorname{Var}_{T}($.$) denotes the sample variance of daily observations, and a "$ " denotes the GMM parameter estimate. $R_{e}^{2}$ and $R_{\xi}^{2}$ identify the average contribution of news-related shocks to the integrated variance of the residuals in the order flow and price change equations and are computed as $R_{e}^{2}=\hat{\sigma} \overline{A_{t}} /\left(\hat{\sigma} \overline{A_{t}}+\hat{s}_{\eta}\right)$ and $R_{\xi}^{2}=\hat{\omega} \overline{A_{t}} /\left(\hat{\omega} \overline{A_{t}}+\hat{s}_{\kappa}\right)$, where $\overline{A_{t}}$ is the sample average of $A_{t}$. The standard errors associated with all the ratios are computed from a Monte Carlo simulation with 5000 replications based on the asymptotic distribution of the GMM estimates.

Appendix Table 2 provides supplemental evidence on the daily relation between the volatility and the flow of news items. The upper (lower) panel reports results from regressions 
of the integrated volatility of price changes (order flow) on the daily flow of all news items, $A_{t}$, US items, $A_{t}^{u s}$, and German items $A_{t}^{g}$. Consistent with the results in Table 2 and the visual evidence in Figure 3, all three regressors are statistically significant. We also report several diagnostics associated with these regressions. Under the column headed "Non-linear", are p-values for chi-squared LM tests excluding squared news terms. None of the tests are significant, providing support for the linear variance functions of our daily model. There is little evidence of residual serial correlation or heteroskedasticity in the price volatility regressions. In the case of order flow, the presence of residual serial correlation indicates that daily changes in the volatility of order flow are not completely accounted for by variations in the flow of news. To see whether this feature of the data materially affected our results, we re-estimated the daily model using the Newey-West weighting matrix allowing for an MA(1) error structure. The parameter estimates (and standard errors) are very similar to those shown in Table 2.

\section{Intraday Data}

Our analysis of the intraday data draws on Evans (2002). The data set constitutes a sequence of irregularly spaced observations on a continuous trading process. At some points in the sample, the gaps between successive trades span many minutes, while at others several trades appear with the same second-by-second time stamp. We do not attempt to directly model these irregular timing patterns. Instead, we use prices, order flow, trading intensity, and news flow measured relative to a fixed five-minute observation interval. One consequence of adopting a fixed observation interval is that there are periods of the day when no transactions take place during an interval. We designate observations from these periods as "missing". Evans (2002) describes how GMM estimation can be modified to deal with these observations and we refer interested readers to that paper for further estimation and testing details.

To estimate the intraday model, we need to be precise about the relation between the prices we observe in the data set and the equilibrium market price. Prices in the data set come in two forms. If a dealer initiating a transactions buys dollars, the transaction price 
equals the ask quote in DMs per dollar offered by the other dealer. We refer to this as the DM purchase price for dollars, $p^{a s k}$. If the dealer initiating a transaction sells dollars, the transaction price will equal the bid quote given by the other dealer. We refer to this as the DM sale price for dollars, $p^{b i d}$. Evans (2002) argues that the lack of transparency in direct dealer trading (and differences between the mechanisms for direct and brokered interdealer trading) allows for the existence of an equilibrium price distribution without introducing arbitrage opportunities.

To formalize this idea, our intraday model assumes that equilibrium in the market at a point in time is described by a distribution of purchase prices and a distribution of sales prices. Let $p_{i}^{a s k}$ and $p_{i}^{b i d}$ denote observed prices drawn randomly from the respective distributions of purchase and sales prices at time $i$. These observed prices are related to the average transaction price, $p_{i}$, by

$$
p_{i}^{o}=p_{i}+\omega_{i}^{o}
$$

for $o=\{a s k$, bid $\} . \omega_{i}^{a s k}$ and $\omega_{i}^{b i d}$ are idiosyncratic shocks that identify the degree to which observed prices differ from the market-wide average. Their size depends on the identity of the dealers whose prices we observe. The model assumes that observed prices are drawn randomly and independently from the cross-sectional distributions of purchase and sale prices every period so that $\omega_{i}^{a s k}$ and $\omega_{i}^{\text {bid }}$ are serially uncorrelated and independently distributed.

Combining (A1) with (9) and (11) in the text, gives us the estimable form of the model

$$
\begin{aligned}
\Delta p_{i}^{a s k} & =D\left(L, n_{i}, A_{i}^{*}\right) x_{i}+\varepsilon_{i}+\omega_{i}^{a s k}-\omega_{i-1}^{a s k}, \\
\Delta p_{i}^{b i d} & =D\left(L, n_{i}, A_{i}^{*}\right) x_{i}+\varepsilon_{i}+\omega_{i}^{b i d}-\omega_{i-1}^{b i d}, \\
C(L)^{-1} x_{i} & =v_{i} .
\end{aligned}
$$

This specification extends the model in Evans (2002) with addition of both another state variable (news arrival) and the equation for order flow, and can be estimated with the same technique. We therefore refer readers to that paper for further details on how the GMM estimates reported in Table 3 are obtained. As in Evans (2002), we set $\gamma$ equal to 100 for 
estimation. We also find that the unrestricted estimates of $\Sigma_{\varepsilon}(0, A), \Sigma_{v}(0, A)$ and $\Sigma_{\omega}(\infty, A)$ are very close to zero, so Table 3 reports estimates where these parameters are restricted to zero. None of these restrictions materially affect the variance decompositions in Table 4 .

Appendix Table 3 provides empirical motivation for the presence of state-dependence in the intraday model. The upper panel reports Wald tests for non-linearity in models of the form:

$$
z_{i}=\theta(L) x_{i}+\theta_{n}(L) x_{i} n_{i}+\theta_{A}(L) x_{i} A_{i}+\varsigma_{i}
$$

All models are estimated by GMM allowing for heteroskedasticity and an MA(1) error structure in the case of $z_{i}=\Delta p_{i}^{a s k}$ and $z_{i}=\Delta p_{i}^{b i d}$. These estimates are then used to construct the Wald test. For the price change models, $\theta_{j}(L)=\theta_{j 1} L^{-4}+\theta_{j 2} L^{-3}+\ldots \theta_{j 6} L$, and for order flow $\theta_{j}(L)=\theta_{j 1} L+\theta_{j 2} L^{2}+\ldots \theta_{j 10} L^{10}$; these specifications capture all the serial correlation in the data (see, Evans 2002 for further details). As the table shows, there is strong evidence to reject the null hypothesis of no state-dependence with respect to trading intensity and the flow of news in both the price equations, but not in the order flow equation. The lower panel reports Glesjer (1969) tests for heteroskedasticity in the shocks to the model in (A2) - (A4) estimated without state-dependence in $D\left(L, n_{i}, A_{i}^{*}\right)$. There is strong evidence against the null of homoskedasticity in all cases with respect to trading intensity. There is also strong evidence of heteroskedasticity related to the flow of news in the case of the $\varepsilon_{i}$ and $v_{i}$ shocks.

Appendix Table 4 reports diagnostics for the GMM estimates of the intraday model. The Wald test for the null of $D(L, 0,0)=D(L, \infty, 0)$ is computed as $\nabla \hat{d}^{\prime}\left(\hat{\Omega}_{\nabla d}\right)^{-1} \nabla \hat{d}$ where

$$
\nabla \hat{d}=\left[\hat{d}_{1}(0,0)-\hat{d}_{1}(\infty, 0), . . . ., \hat{d}_{6}(0,0)-\hat{d}_{6}(\infty, 0)\right]
$$

and $\hat{\Omega}_{\nabla d}$ is the estimated asymptotic covariance matrix of $\nabla d$. The other Wald tests use the coefficients in $D\left(L, n, A^{*}\right)$ analogously. To test for misspecification in the $d_{j}\left(n, A^{*}\right)$ and $\Sigma_{j}(n, A)$ functions, we use the GMM version of the LM test developed by Newey and West (1987). In the case of the $d_{j}\left(n, A^{*}\right)$ functions, we consider alternative specifications of the form $\tilde{d}_{j}\left(n, A^{*}\right)=d_{j}\left(n, A^{*}\right)+\varphi_{j} n$ for type (i) tests, and $\tilde{d}_{j}\left(n, A^{*}\right)=d_{j}\left(n, A^{*}\right)+\varphi_{j} A^{*}$ for 
type (ii). To test the null hypothesis that $\varphi_{j}=0$ for all $j$, we use the two-step procedure suggested by Greene (1997). First, we compute the derivative for the GMM criterion function with $\tilde{d}_{j}\left(n, A^{*}\right)$ replacing $d_{j}\left(n, A^{*}\right)$ at the GMM estimates with $\varphi_{j}=0$. We then calculate the Wald statistic for the null hypothesis that this vector of derivatives equals zero. In the case of the variance functions $\Sigma_{\omega}(n)$ and $\Sigma_{\varepsilon}(n)$, the alternative specifications take the form of $\tilde{\Sigma}_{\varpi}(n, A)=\Sigma_{\varpi}(n, A)+\varphi n$ for type (i) and $\tilde{\Sigma}_{\varpi}(n, A)=\Sigma_{\varpi}(n, A)+\varphi A$ for type (ii) where $\Sigma(n, A)=\left\{\Sigma_{\varepsilon}(n, A), \Sigma_{\omega}(n, A), \Sigma_{v}(n, A)\right\}$. None of these statistics are statistically significant. This suggests that the model did manage to incorporate most of the statedependence in return and order flow dynamics. The lower panel reports autocorrelations for the estimated shocks. The shocks are calculated from the GMM estimates and standardized as $\tilde{\varpi}_{i}^{2}=\varpi_{i}^{2}\left[\hat{\Sigma}_{\varpi}\left(n_{i}, A_{i}\right)\right]^{-1}$ where $\varpi_{i}$ denotes the shock in question. These statistics show there is some residual heteroskedasticity not accounted for by the state variables.

The variance decompositions reported in Table 4 are computed as follows. First we write the price change dynamics implied by the GMM estimates as

$$
\Delta p_{i}=B\left(L, n_{i}, A_{i}^{*}\right) v_{i}+\varepsilon_{i}
$$

where $B\left(L, n, A^{*}\right)=D\left(L, n, A^{*}\right) L^{4} C(L)$. Next, we consider the $k$-period price change, $\Delta^{k} p_{i} \equiv \Sigma_{j=0}^{k-1} \Delta p_{i+j}$, implied by this equation:

$$
\Delta^{k} p_{i}=\sum_{j=0}^{k-1} \varepsilon_{i-j}+B\left(L, k, n_{i}, A_{i}^{*}\right) v_{i}
$$

where $B\left(L, k, n_{i}, A_{i}^{*}\right)=\sum_{j=0}^{k-1} B\left(L, L^{j} n_{i}, L^{j} A_{i}^{*}\right) L^{j}$. Since the $v_{i}$ and $\varepsilon_{i}$ shocks are independent and serially uncorrelated, the variance of price changes is

$$
\operatorname{Var}\left(\Delta^{k} p_{i}\right)=\sum_{j=0}^{k-1} \Sigma_{\varepsilon}\left(n_{i-j}\right)+\operatorname{Var}\left(B\left(L, k, n_{i}, A_{i}^{*}\right) v_{i}\right)
$$

The upper panel of Table 4 reports the contribution of the second term to the variance of price changes for different horizons $k$, and trading intensities $n_{i}$ with $A_{i}^{*}=A_{i}=1$. The calculations 
use the GMM estimates of $D\left(L, n, A^{*}\right), C(L), \Sigma_{\varepsilon}(n, A)$ and $\Sigma_{v}(n, A)$ reported in Table 3. Standard errors (shown in parenthesis) are computed from 5000 Monte Carlo simulations based on the asymptotic distribution of the GMM estimates. (For the $k=\infty$ case, we note that prices can be written as $p_{i}=\bar{p}_{i}+I(0)$ terms, where $\Delta \bar{p}_{i}=\varepsilon_{i}+B\left(1, n, A^{*}\right) v_{i}$. The contribution of order flow can therefore be calculated as $B\left(1, n, A^{*}\right)^{2} \Sigma_{v}(n, A) / \operatorname{Var}\left(\Delta \bar{p}_{i}\right)$.) The middle panel reports the analogous contributions for the case where $A_{i}^{*}=A_{i}=0$. The lower panel reports the Monte Carlo p-value for the null hypothesis that there is no increase in the contribution of order flow shocks when news arrives.

Finally, we consider whether time-aggregation of our intraday model can account for the negative estimates of $\phi$ in the daily model. For this we calculate $x_{i}^{*} \equiv \frac{1}{D(1)} \sum_{j=1}^{288} D(L) x_{i-j}$ where $D(L)$ is the polynomial on order flow from the model in (A2) - (A4) estimated without state-dependence. Notice that the 5:00 BST observation on $x_{i}^{*}$ each day (i.e., $x_{t, 216}^{*}$ ) should closely approximate $x_{t}^{*}$ in the daily model. To examine whether our intraday model can account for the negative estimates of $\phi$ found in the daily data, we then estimate the regression

$$
x_{t}=a_{0} x_{t, 216}^{*}+a_{1} \Delta p_{t}+\zeta_{t}
$$

This regression corresponds to the combination of equations (6) and (8) of the daily model. The OLS estimate of $a_{0}$ is 0.948 while the estimate of $a_{1}$ is -1.963 , close to the estimate of -2.051 found for $\phi$ in Table 2 . 


\section{Appendix Table 1}

\section{Daily Model Estimates with Scheduled Announcements}

$\begin{array}{ll}\Delta p_{t}=\alpha x_{t}^{*}+\xi_{t}+v_{t} & \text { with } \operatorname{VAR}\left(\xi_{t}\right)=\omega A_{t}, \operatorname{VAR}\left(\kappa_{t}\right)=s_{\kappa} \\ x_{t}=x_{t}^{*}+x_{t}^{+} & \text {with } x_{t}^{*}=e_{t}+\eta_{t}, \operatorname{VAR}\left(e_{t}\right)=\sigma A_{t}, \operatorname{VAR}\left(\eta_{t}\right)=s_{\eta}, x_{t}^{+}=\phi \Delta p_{t}\end{array}$

\begin{tabular}{|c|c|c|c|c|}
\hline \multirow[b]{2}{*}{ Parameters } & \multicolumn{2}{|c|}{ All News } & \multicolumn{2}{|c|}{ US vs German News } \\
\hline & Estimate & Std. Err. & Estimate & Std. Err. \\
\hline $\begin{array}{cc}\alpha & \\
\phi & \\
s_{\kappa} & \\
s_{\eta} & \\
\omega & \\
\sigma & \\
& \omega_{u s} \\
& \omega_{g} \\
& \sigma_{u s} \\
& \sigma_{g}\end{array}$ & $\begin{array}{r}0.031 \\
-2.036 \\
108.725 \\
5.506 \\
8.523 \\
0.415\end{array}$ & $\begin{array}{l}(0.002) \\
(0.175) \\
(5.596) \\
(0.381) \\
(5.019) \\
(0.267)\end{array}$ & $\begin{array}{r}0.031 \\
-2.028 \\
108.582 \\
5.477\end{array}$ & $\begin{array}{r}(11.636) \\
(4.871) \\
(0.664) \\
(0.265)\end{array}$ \\
\hline Variance Ratios & Ratio & Std. Err. & Ratio & Std. Err. \\
\hline$R_{\Delta p}^{2}($ direct $)$ & 0.014 & (0.009) & 0.018 & $(0.011)$ \\
\hline$R_{\Delta p}^{2}($ indirect $)$ & 0.028 & $(0.020)$ & 0.025 & $(0.018)$ \\
\hline$R_{\Delta p}^{2}($ total $)$ & 0.042 & $(0.026)$ & 0.044 & $(0.026)$ \\
\hline
\end{tabular}

Notes: The table reports GMM parameter estimates and asymptotic standard errors (corrected for heteroskedasticity) in parentheses. The index $A_{t}$ is constructed as the sum of the absolute standardized forecast errors associated with scheduled macro announcements on each day. We include U.S. announcements on: Non Farm Payroll, Durable Goods, Trade Balance, and Unemployment Claims, and German announcements on: the Current A/C, Employment, GDP, Import Prices, Industrial Production, M3, Manufacturing Orders, Manufacturing Output, Producer Prices, Retail Sales, the Trade Balance, Whole Sale Prices, and the Cost of Living Index. The standard errors reported for the variance ratios are computed from a Monte Carlo experiment with 5000 replications. $R_{\Delta p}^{2}($ direct $)$ and $R_{\Delta p}^{2}$ (indirect) are the fraction of the daily variance in prices attributed to news arrival via the direct and indirect channels. 


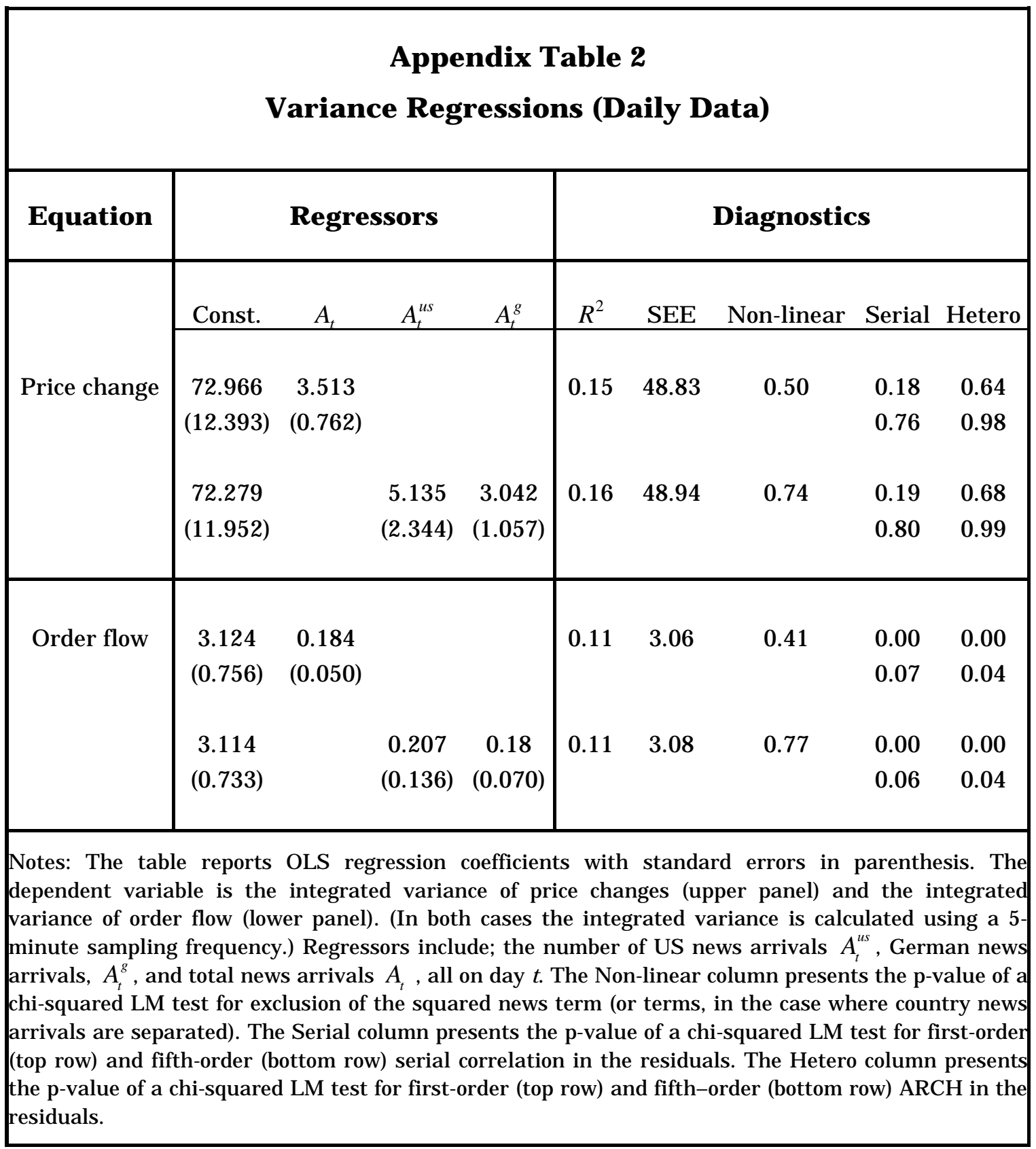




\section{Appendix Table 3}

\section{Tests for State-Dependency (Intraday Data)}

\begin{tabular}{|c|c|c|c|c|}
\hline Equation & \multicolumn{3}{|c|}{ Non-linearity } & (p-value) \\
\hline $\begin{array}{l}\Delta p^{a s k} \\
\Delta p^{b i d} \\
x\end{array}$ & $\begin{array}{r}113.211 \\
103.115 \\
8.411\end{array}$ & $\begin{array}{l}(0.00) \\
(0.00) \\
(0.21)\end{array}$ & $\begin{array}{r}14.247 \\
21.331 \\
4.218\end{array}$ & $\begin{array}{l}(0.03) \\
(0.00) \\
(0.65)\end{array}$ \\
\hline \multicolumn{5}{|c|}{ Heteroskedasticity } \\
\hline $\begin{array}{l}\varepsilon_{t} \\
\omega_{t}^{a s k} \\
\omega_{t}^{b i d} \\
v_{t}\end{array}$ & $\begin{array}{r}797.274 \\
5.514 \\
3.197 \\
6787.326\end{array}$ & $\begin{array}{l}(0.00) \\
(0.02) \\
(0.08) \\
(0.00)\end{array}$ & $\begin{array}{r}4.774 \\
1.846 \\
0.398 \\
10.575\end{array}$ & $\begin{array}{l}(0.03) \\
(0.17) \\
(0.53) \\
(0.00)\end{array}$ \\
\hline
\end{tabular}

Notes: The upper panel reports Wald statistics and p-values for the null hypothesis of zero coefficients on the terms listed at the head of each column in models of the form:

$$
z_{i}=\Theta(L) x_{i}+\Theta(L) x_{i} n_{i}+\Theta(L) x_{i} A_{i}^{*}+w_{i} .
$$

All models were estimated by GMM allowing for heteroskedasticity and an MA(1) error structure in the case of $z_{i}=\Delta p_{i}^{\text {ask }}$ and $z_{i}=\Delta p_{i}^{\text {bid }}$. These estimates are then used to construct the Wald test. For the price change models, $\Theta(L)=\theta_{1} L^{-4}+\theta_{2} L^{-3}+\ldots .+\theta_{6} L$ and for order flow, $\Theta(L)=\theta_{1} L+\theta_{2} L^{2}+\ldots . . \theta_{10} L^{10} . A_{i}^{*}$ and $A_{i}$ are a dummy variables equal to one if there was a macro news arrival during the previous 15-mintues (i.e. 3 observation windows) or previous 5-mintues respectively. The lower panel reports the results of Glesjer (1969) tests for heteroskedasticity in the variance of each shock using the variables listed at the head of each column. The shock $v_{i}$ is the innovation to the $\operatorname{AR}(10)$ model for order flow, while $\varepsilon_{i}, \omega_{i}^{\text {ask }}$, and $\omega_{i}^{\text {bid }}$ are the shocks from

$$
\begin{aligned}
& \Delta p_{i}^{a s k}=\Theta(L) x_{i}+\varepsilon_{i}+\omega_{i}^{a s k}-\omega_{i-1}^{a s k} \\
& \Delta p_{i}^{b i d}=\Theta(L) x_{i}+\varepsilon_{i}+\omega_{i}^{b i d}-\omega_{i-1}^{b i d}
\end{aligned}
$$

estimated jointly by GMM. 


\section{Appendix Table 4}

\section{Diagnostics for The Intraday Model}

Wald Test for $D(L, 0,0)=D(L, \infty, 0)$

Wald Test for $D(L, 0,1)=D(L, \infty, 1)$

Wald Test for $D(L, 0,1)=D(L, 0,1)$

Wald Test for $D(L, \infty, 1)=D(L, \infty, 0)$

$\begin{array}{crr}\frac{\text { Statistic }}{250.731} & & \text { P-value } \\ 19.130 & & (0.001) \\ 24.039 & (0.004) \\ 17.882 & (0.001) \\ & (0.007)\end{array}$

Test (i) for misspecification in $D\left(L, n_{i}, A_{i}^{*}\right)$

0.324

6.097

$(0.999)$

Test (ii) for misspecification in $D\left(L, n_{i}, A_{i}^{*}\right)$

Test (i) for misspecification in $\Sigma_{\varepsilon}\left(n_{i}, A_{i}\right)$

Test (ii) for misspecification in $\Sigma_{\varepsilon}\left(n_{i}, A_{i}\right)$

0.866

$(0.412)$

$(0.352)$

Test (i) for misspecification in $\Sigma_{\omega}\left(n_{i}, A_{i}\right)$

0.173

$(0.677)$

Test (ii) for misspecification in $\Sigma_{\omega}\left(n_{i}, A_{i}\right)$

0.398

$(0.528)$

Test (i) for misspecification in $\Sigma_{v}\left(n_{i}, A_{i}\right)$

Test (ii) for misspecification in $\Sigma_{v}\left(n_{i}, A_{i}\right)$

0.721

(0.396)

2.518

$(0.113)$

0.092

$(0.762)$

\section{Squared Residual Autocorrelations (Std. Errs.)}

\begin{tabular}{|cccccccc} 
& $\mathrm{Lag}=1$ & 2 & 3 & 4 & 5 & 6 & 12 \\
\hline Residual & & & & & & & \\
$\varepsilon_{i}^{2} / \Sigma_{\varepsilon}\left(n_{i}, A_{i}\right)$ & 0.091 & 0.038 & 0.048 & 0.162 & 0.028 & 0.058 & 0.019 \\
& $(0.028)$ & $(0.019)$ & $(0.028)$ & $(0.135)$ & $(0.015)$ & $(0.021)$ & $(0.008)$ \\
$\left(\omega_{i}^{a s k}\right)^{2} / \Sigma_{\omega}\left(n_{i}, A_{i}\right)$ & 0.068 & 0.015 & 0.015 & -0.015 & 0.002 & 0.019 & 0.014 \\
& $(0.025)$ & $(0.016)$ & $(0.020)$ & $(0.011)$ & $(0.010)$ & $(0.012)$ & $(0.011)$ \\
$\left(\omega_{i}^{\text {bid }}\right)^{2} / \Sigma_{\omega}\left(n_{i}, A_{i}\right)$ & 0.058 & 0.022 & 0.009 & 0.005 & -0.003 & 0.010 & 0.023 \\
& $(0.024)$ & $(0.010)$ & $(0.012)$ & $(0.012)$ & $(0.009)$ & $(0.011)$ & $(0.014)$ \\
$v_{i}^{2} / \Sigma_{v}\left(n_{i}, A_{i}\right)$ & 0.068 & 0.032 & 0.039 & 0.033 & 0.000 & 0.022 & -0.009 \\
& $(0.026)$ & $(0.017)$ & $(0.017)$ & $(0.017)$ & $(0.017)$ & $(0.018)$ & $(0.007)$ \\
& & & & & & &
\end{tabular}

Notes: The table reports diagnostic tests for the estimated intraday model shown in Table 3. The upper panel reports Wald tests for state-dependency in $D\left(L, n_{i}, A_{i}^{*}\right)$. The second panel reports LM-type tests for misspecification in the estimated $d_{j}\left(n_{i}, A_{i}^{*}\right)$ and $\Sigma_{j}\left(n_{i}, A_{i}\right)$ functions. Type (i) and (ii) tests consider misspecification with respect to trade intensity $n_{i}$ and news arrival dummy $A_{i}$, respectively. ( $A_{i}^{*}$ and $A_{i}$ are a dummy variables equal to one if there was a news arrival during the previous 15mintues-i.e. 3 observation windows-or previous 5-mintues respectively.) The lower panel reports autocorrelations in the standardized squared shocks. 